\title{
Production of Pure Drug Nanocrystals and Nano Co-crystals by Confinement Methods
}

\section{Fontana, Flavia}

2018-06

Fontana , F , Figueiredo , P I , Zhang , P , Hirvonen , J T , Liu , D \& Almeida Santos , H 2018

, ' Production of Pure Drug Nanocrystals and Nano Co-crystals by Confinement Methods ' , Advanced Drug Delivery Reviews , vol. 131 , pp. 3-21 . https://doi.org/10.1016/j.addr.2018.05.002

http://hdl.handle.net/10138/301442

https://doi.org/10.1016/j.addr.2018.05.002

cc_by_nc_nd

acceptedVersion

Downloaded from Helda, University of Helsinki institutional repository.

This is an electronic reprint of the original article.

This reprint may differ from the original in pagination and typographic detail.

Please cite the original version. 


\section{Accepted Manuscript}

Production of pure drug nanocrystals and Nano Co-crystals by confinement methods

Flavia Fontana, Patricia Figueiredo, Pei Zhang, Jouni T. Hirvonen, Dongfei Liu, Helder A. Santos

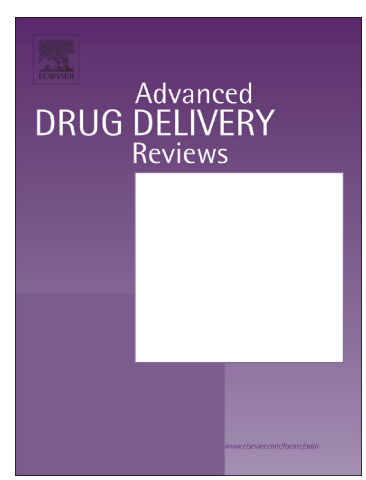

PII:

S0169-409X(18)30083-8

DOI: doi:10.1016/j.addr.2018.05.002

Reference: ADR 13302

To appear in: Advanced Drug Delivery Reviews

Received date: 28 February 2018

Revised date: 1 May 2018

Accepted date: 3 May 2018

Please cite this article as: Flavia Fontana, Patricia Figueiredo, Pei Zhang, Jouni T. Hirvonen, Dongfei Liu, Helder A. Santos, Production of pure drug nanocrystals and Nano Co-crystals by confinement methods. The address for the corresponding author was captured as affiliation for all authors. Please check if appropriate. Adr(2018), doi:10.1016/ j.addr.2018.05.002

This is a PDF file of an unedited manuscript that has been accepted for publication. As a service to our customers we are providing this early version of the manuscript. The manuscript will undergo copyediting, typesetting, and review of the resulting proof before it is published in its final form. Please note that during the production process errors may be discovered which could affect the content, and all legal disclaimers that apply to the journal pertain. 


\section{Production of Pure Drug Nanocrystals and Nano Co-crystals by Confinement Methods}

Flavia Fontana ${ }^{\mathrm{a}, \dagger}$, Patricia Figueiredo ${ }^{\mathrm{a}, \dagger}$, Pei Zhang ${ }^{\mathrm{a}}$, Jouni T. Hirvonen ${ }^{\mathrm{a}}$, Dongfei Liu ${ }^{\mathrm{a}, \mathrm{b}}$, and Helder A. Santos ${ }^{\mathrm{a}, \mathrm{b}, *}$

${ }^{a}$ Drug Research Program, Division of Pharmaceutical Chemistry and Technology, Faculty of Pharmacy, University of Helsinki, Helsinki FI-00014, Finland

${ }^{\mathrm{b}}$ Helsinki Institute of Life Sciences (HiLIFE), University of Helsinki, Helsinki FI-00014, Finland

${ }^{\dagger}$ These authors contributed equally to the work.

* Corresponding author: Drug Research Program, Division of Pharmaceutical Chemistry and Technology, Faculty of Pharmacy, University of Helsinki, Helsinki FI-00014, Finland.

E-mail address: helder.santos@helsinki.fi (H. A. Santos) 


\begin{abstract}
The use of drug nanocrystals in the drug formulation is increasing due to the large number of poorly water-soluble drug compounds synthetized and due to the advantages brought by the nanonization process. The downsizing processes are done using a top-down approach (milling and homogenization currently employed at the industrial level), while the crystallization process is performed by bottom-up techniques (e.g., antisolvent precipitation to the use of supercritical fluids or spray and freeze drying). In addition, the production of nanocrystals in confined environment can be achieved within microfluidics channels. This review analyzes the processes for the preparation of nanocrystals and co-crystals, divided by top-down and bottom-up approaches, together with their combinations. The combination of both strategies merges the favorable features of each process and avoids the disadvantages of single processes. Overall, the applicability of drug nanocrystals is highlighted by the widespread research on the production processes at the engineering, pharmaceutical, and nanotechnology level.
\end{abstract}

Keywords: Nanocrystals; Co-crystals; Drug; Top-down; Bottom-up; Milling; Homogenization; Microfluidics; Supercritical fluids; Spray dryer 


\section{Table of Contents}

1. Introduction

1.1.Pure Drug Nanocrystals and Co-crystals in Drug Delivery

1.1.1.Pure Nanocrystals

1.1.2. Co-crystals

2. Production Methods of Drug Nanocrystals

2.1. Top-down Approach

2.1.1. Wet Media Milling

2.1.2. High-Pressure Homogenization

2.2. Bottom-up methods

2.2.1. Solvent-Antisolvent

2.2.1.1. Conventional Methods

2.2.1.2. Microfluidics

2.2.2. Supercritical Fluid Technology

2.2.3. Solvent Evaporation and Spray Drying

2.3. Combination of Bottom-up and Top-Down Approaches

3. Challenges for Scale-up Production

4. Conclusion and Future Prospective

5. References 


\section{Introduction}

Poor solubility of drug molecules is a challenging problem in drug discovery and development, in which approximately $70-90 \%$ of the new compounds belong to the Biopharmaceutics Classification System (BCS) class II or class IV [1]. The formulation of poorly water-soluble drug compounds usually encounters low oral bioavailability and unpredictable absorption, because of their low solubility and dissolution rate, and consequently, their therapeutic effect is reduced [2].

Different types of nanosystems have been approved to enhance the solubility of poorly watersoluble drugs, to target the drugs to the desired location of action with increased precision, to control their release, and to improve the transport across biological barriers. The nanosystems formulated either for oral or parenteral drug delivery in the EU market include liposomes, nanoemulsions, polymeric therapeutics, polymeric NPs, nanocomplexes, and nanocrystals (Figure 1) $[3-5]$.

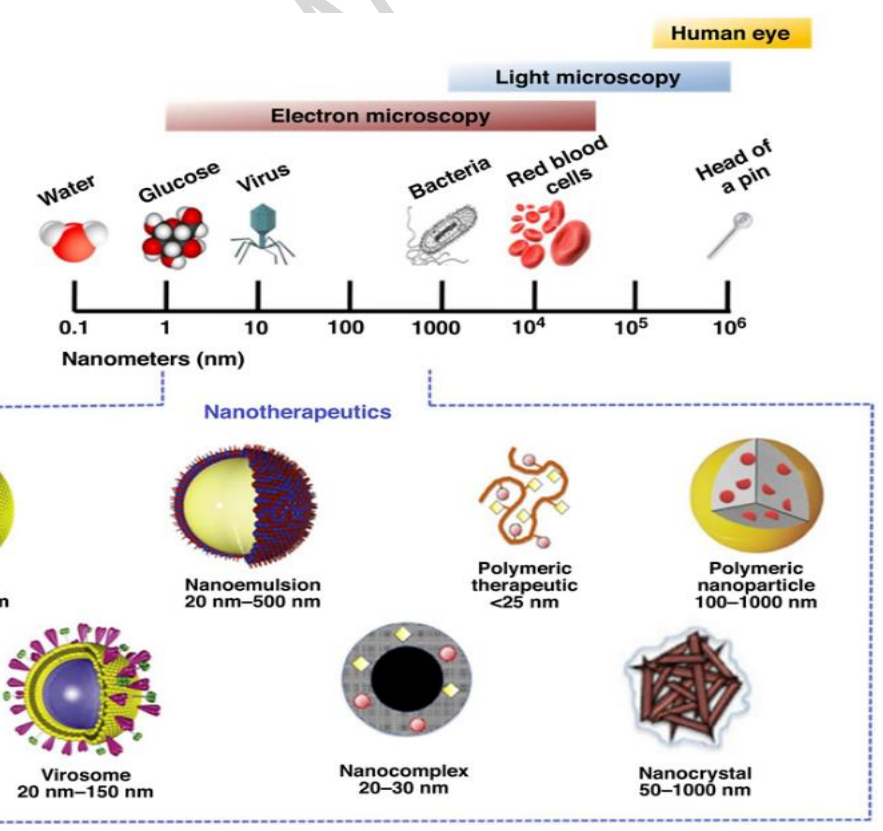

Figure 1. Overview of the nanosystems developed for oral or parenteral drug delivery in the EU market. Reproduced with permission from ref. [4], () 2018, Elsevier B.V. 
Another strategy that has been exploited to increase the solubility of poorly water-soluble drugs is the use of co-solvents (e.g., water or ethanol) or solubilizing agents (e.g., surfactants like Cremophor EL). However, this leads to the increase of the side effects or toxic reaction to the body due to the solubilizing agents or traces of the organic solvents $[2,6]$. Therefore, there is an urgent need for the development of safe and effective approaches to increase the solubility and bioavailability of poorly water-soluble drugs. In this way, different chemical and physical modifications have been performed, including salt formation of ionizable drugs [7], drug complexation with cyclodextrins [8,9] or conjugation to dendrimers [10], preparation of drug dispersions in nanocarriers like self-microemulsifying drug delivery systems [11], nano/micro emulsions [12] or other lipid-based formulations [13]. In addition, particle size reduction to the micro/nano-meter range can be applied to formulate poorly water-soluble drugs, leading to a significant increase of the surface-to-volume ratio, and consequently, to an increase of dissolution rate [2]. Micronization is a very simple technology that can use jet milling or wet milling to reduce the particle size of drugs belonging to the poorly water-soluble drugs. However, many of the new drugs show such a low solubility that micronization does not effectively increase the bioavailability, leading to the nanonization of micronized drug particles by producing drug nanocrystals [14]. The production of drug nanocrystals has been developed since the beginning of the $1990 \mathrm{~s}[2,6]$.

Drug nanocrystals are an interesting approach for the delivery of poorly water-soluble drugs, because they are a carrier-free colloidal system in the nanometer range (100-1000 nm), with a theoretical drug loading of $100 \%[6,15]$. When dispersed in a liquid media, they need to be stabilized with surfactants or polymeric steric stabilizers $[6,16]$. The main role of the stabilizers is to prevent the unstable particles from aggregation and/or Ostwald ripening during storage of the drug nanocrystal suspensions [17]. The dispersion media to formulate drug nanocrystal suspensions can be water or other aqueous solutions and non-aqueous solutions [6, 16]. The production of 
nanocrystals after reducing the particle size to the nanosized range, leads to the modification of the intrinsic properties of the raw material, including its thermodynamic and kinetic characteristics [18]. Two different approaches can be used for the production of drug nanocrystals with desired particle size and size distribution: (1) top-down technologies that involve high-energy mechanical forces to coarse the drug powder, which are provided by media milling or high-pressure homogenization, and (2) bottom-up methods, where nucleation and consequent crystal growth from solutions take place, triggered for example by adding an antisolvent or removing the solvent [19].

In this review, we first introduce the general features of pure drug nanocrystals and co-crystals in drug delivery. Then, the principal approaches for the production of nanocrystals are addressed, namely the top-down methods like pearl-milling, high-pressure homogenization and ultrasonication. Bottom-up methods, including the solvent-antisolvent by a conventional method or using microfluidics, the supercritical fluid and the solvent removal are described and discussed. Finally, combinative technologies for the production of drug nanocrystals are presented and discussed, as well as the challenges for scale-up production of drug nanocrystals.

\subsection{Pure Drug Nanocrystals and Co-crystals in Drug Delivery}

\subsubsection{Drug Nanocrystals}

Depending on the production method, transforming drug microcrystals to drug nanoparticles can lead to the production of a crystalline or an amorphous product. Although an amorphous drug nanoparticle should not be called nanocrystal, they are often referred as "nanocrystals in the amorphous state" [6]. The production of drug nanocrystals allows a reduction on the size of poorly water-soluble drug particles to the nanometer range, changing the thermodynamic and kinetic characteristics of the drug, solving its biopharmaceutical delivery problems $[15,18]$. The delivery issues that poorly water-soluble drugs can encounter are: (i) low bioavailability after oral administration; (ii) low penetration into the skin, and consequent low dermal bioavailability; and 
(iii) the need for a large injection volume for intravenous (i.v.) administration that leads to undesired side effects $[15,16]$. To overcome the solubility problems, the production of drug nanocrystals leads to an increase in saturation solubility, an increase in dissolution rate, and an increased adhesiveness to surface/cell membranes (Figure 2) [15, 16]. The physical background of these effects is described in detail below. Furthermore, the general features of pure drug nanocrystals and co-crystals (i.e., mixture of two or more different components in a crystalline form) are also discussed and summarized in Table $\mathbf{1 .}$
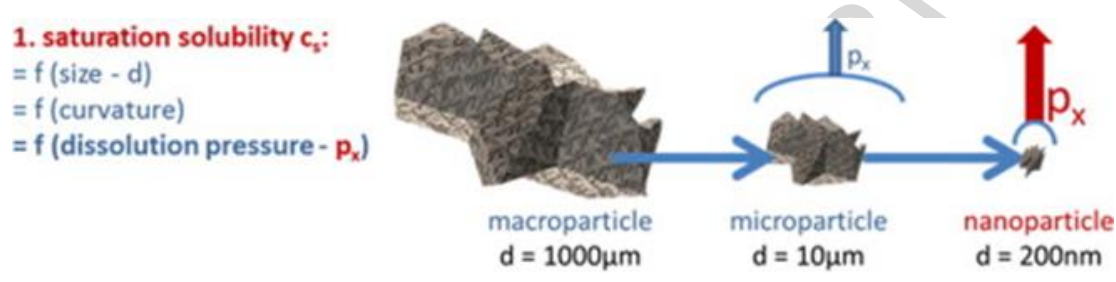

2. dissolution velocity $\mathrm{dc} / \mathrm{dt}$ : $=f\left(\right.$ saturation solubility $\left.-c_{5}\right)$ $=f$ (diffusional distance) $=f($ total surface area- $A)$
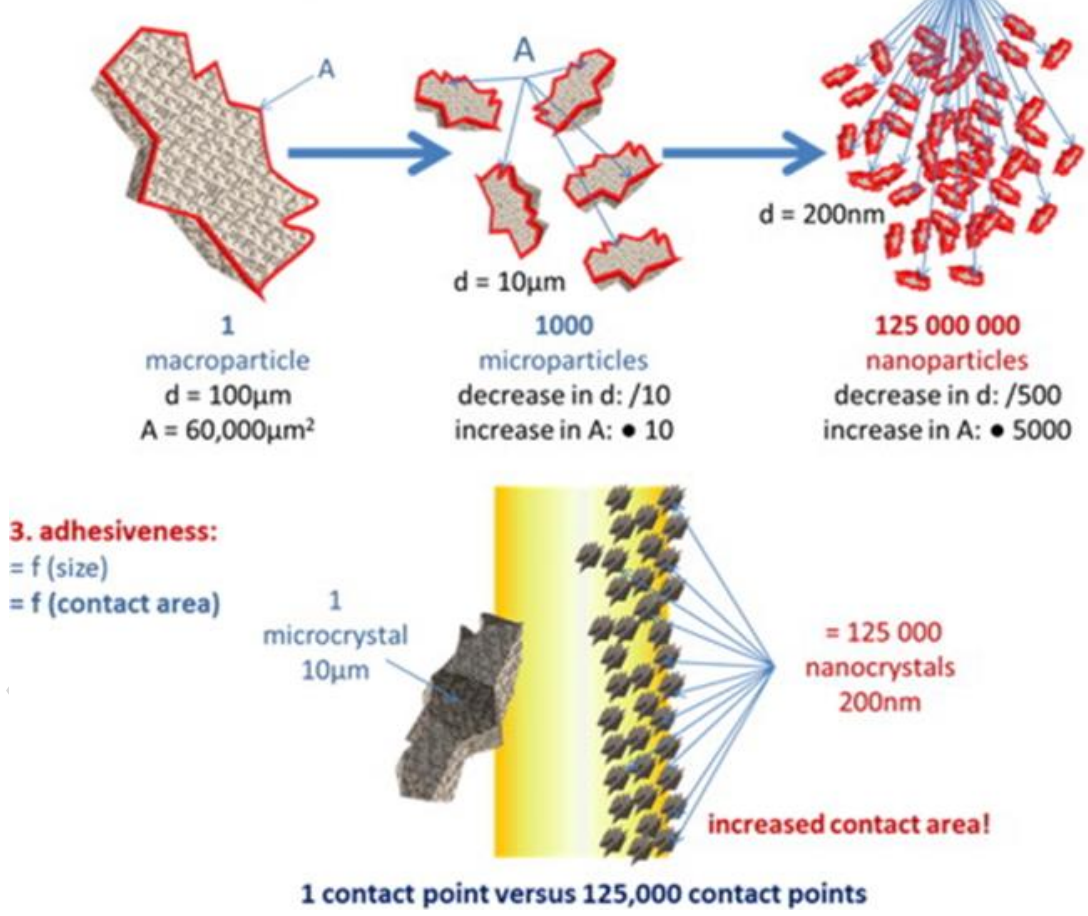

Figure 2. General features of drug nanocrystals: (1) increased saturation solubility due to increased dissolution pressure of strongly curved small nanocrystals; (2) increased dissolution rate due to increased surface area; and (3) increased adhesiveness of nanomaterial due to increased contact area of small versus large particles. Reproduced with permission from ref. [15], (C) 2011, Elsevier B.V. 
Table 1. Summary of the general features of pure drug nanocrystals and co-crystals for drug delivery [16].

\section{Pure Drug Nanocrystals}

- $\quad$ Particle size below $1 \mu \mathrm{m}$

- $100 \%$ drug (no carrier)

- Generally needed to be stabilized by surface active agent

- Crystalline or amorphous structure (Amorphous state offers advantages)

- Increased dissolution rate

- Increased saturation solubility

- Increased adhesiveness to surface/cell membranes

- Long-term stability

- Increased bioavalibility of the drug

- Possible nanotoxicity and side effects

\section{Co-crystals}

- Improving the physicochemical properties of active pharmaceutical ingredients (APIs):

- Dissolution rate

- Intrinsic solubility

- Melting point

- Hygroscopicity

- Compressibility

Bulk density

Friability

Drug nanocrystals can reach an increased dissolution rate as compared to bulk drug as a consequence of the large interfacial area due to the decreased particle size, which can be explained by the Noyes-Whitney equation (Eq. 1) [20, 21]:

$$
\frac{d C}{d t}=\frac{D S}{V h}\left(C_{S}-C_{t}\right)
$$

where, $d C / d t$ is the rate (concentration change as a function of time), $D$ is the diffusion coefficient, $S$ is the surface area, $V$ is the dissolution volume, $h$ is the diffusion layer thickness, $C_{S}$ is the saturation concentration and $C_{t}$ is the concentration at time $t[16,17]$. Thus, particle size is an important factor in the determination of dissolution rate. For example, by reducing the particle size from $50 \mu \mathrm{m}$ to $500 \mathrm{~nm}$, the drug dissolution rate will increase 100 times [17]. 
In general, the saturation solubility is a constant that depends on the physicochemical properties of a specific compound, dissolution medium and temperature, as well as the crystalline structure (i.e., lattice energy) and particle size [16]. For example, homogenization process produces amorphous fraction with high inner energy that contributes to an increased solubility of the substance. In addition, the saturation solubility increases when the particle size is reduced below $1 \mu \mathrm{m}$ [16]. This effect can be explained by the Ostwald-Freundlich equation that directly describes the relation between the saturation solubility of the drug $\left(C_{S}\right)$ and the particle size $(r)($ Eq. 2) $[18,22,23]$ :

$$
\log \frac{C_{S}}{C_{\alpha}}=\frac{2 \sigma V}{2.303 R T \rho r}
$$

where, $C_{S}$ is the saturation solubility, $C_{\alpha}$ is the solubility of large particles, $\sigma$ is the interfacial tension of the substance, $V$ is the molar volume of the particle material, $R$ is the gas constant, $T$ is the absolute temperature, $\rho$ is the density of the solid, and $r$ is the radius $[16,23]$. Thus, an increase in the saturation solubility presents two advantages: (1) enhanced dissolution rate due to an increased in concentration gradient $\left(C_{S}-C_{t}\right) / h$, according to the Noyes-Whitney equation, and (2) increased concentration gradient between gut lumen and blood that promote the permeation and absorption by passive diffusion $[6,16]$.

Drug nanocrystals present also an increased adhesiveness to surface/cell membranes compared to the microparticles, because of the reduced size and increased contact area of the small particles. Consequently, an improvement of oral absorption of poorly water-soluble drugs is observed, along with the increased saturation solubility and dissolution rate, due to the increased residence time, all factors presenting a positive impact on the bioavailability of the drug [16, 24].

In addition, the usage of drug nanocrystals in their amorphous state presents an advantage, because they have higher saturation solubility compared to their crystalline form. Consequently, the highest saturation solubility can be ideally obtained by combining the nanometer size and amorphous state of drug nanocrystals $[6,16]$. The transformation of crystalline structures can occur during the fabrication process of drug nanocrystals, leading to an increase on the amorphous fraction in the 
particle or even forming completely amorphous particles, which make the drugs dissolving more rapidly [16]. However, the capacity to maintain the amorphous state during the shelf life of pharmaceutical products needs to be considered [6].

Another characteristic feature of drug nanocrystal suspensions is the long-term physical stability after stabilization with a stabilizer, leading to an absence of aggregation of nanocrystals and Ostwald ripening phenomenon. Ostwald ripening phenomenon happens when the solute concentration near the smaller particles is higher than the large particles due to the increased saturation solubility of small particles. Consequently, the molecules in the proximity of the small particles will deposit into the large particles driven by the concentration gradient, leading to the formation of microparticles as a result of the recrystallization on the surface of the larger particles. However, the differences in the saturation solubility due to the different particle sizes can be prevented when a narrow size distribution of drug nanocrystals is achieved [16]. Generally, the drug nanocrystal suspensions are thermodynamically unstable systems due to their large interfacial area, and consequent high interfacial free energy. The surface free energy ( $\Delta G$ or 'Gibbs energy'), associated with this area is explained by the following equation (Eq. 3):

$$
\Delta G=\gamma_{S L} \times \Delta A-T \Delta S
$$

where, $\Delta A$ is the change in surface area, $\gamma_{S L}$ is the interfacial tension between the solid and liquid interface, $T$ is the absolute temperature, and $\Delta S$ is the change in entropy of the system. Thus, the particles in a nanosuspension have a tendency to aggregate to minimize the surface energy of the system [4].

To achieve a stable drug nanocrystal suspension, the addition of a surface active agent is required to provide electrostatic and steric repulsion between the nanocrystals, preventing the aggregation of drug nanocrystals [16]. The addition of stabilizers will inhibit the aggregation by increasing the activation energy of the process [25]. Several surface active agents can be used to stabilize drug nanocrystal suspensions, including ionic surfactants [e.g., sodium dodecyl sulfate (SDS) [26], 
sodium lauryl sulfate (SLS) [27], poly(ethylene imine) (PEI) [28], chitosan [29]], non-ionic surfactants [e.g., polysorbates, sorbitan esters, and Pluronics [30]], and polymers [e.g., polyvinyl pyrrolidone (PVP) [31], hydroxypropyl methyl cellulose (HPMCs) [25], and hydroxypropyl cellulose (HPCs) [27], d- $\alpha$-tocopherol polyethylene glycol 1000 succinate (TPGS 1000) [32], polyethylene glycols (PEGs) [33], polyvinyl alcohols (PVAs) [31], amphiphilic amino acid copolymers [34], crystalline cellulose [35]]. In general, ionic surfactants are used to maintain the particles separated via electrostatic repulsion, while the non-ionic surfactants and polymeric stabilizers can be used to establish a steric barrier against aggregation [33, 36]. Moreover, the combination of an electrostatic and a steric stabilizer, also called 'electrosteric stabilization', showed better effectiveness for stabilizing drug nanocrystals [4, 33]. For example, poloxamer F68 along with chitosan derivatives were combined to improve the stability of itraconazole nanocrystals, improving the stability of the nanocrystals when compared to F68 alone [37]. The selection of a suitable stabilizer for a drug nanocrystal suspension is still based on the trial-and-error method. The particle size and size reduction kinetics of the produced drug nanocrystal suspensions is affected by the type and concentration of stabilizer used. For example, when the concentration of the stabilizer is below the optimum concentration, the particle growth occurs due to the incomplete covering of the nanocrystals surface by the stabilizer; while in the case of stabilizer overdosing, particle growth occurs as a result of Ostwald ripening phenomenon $[4,38]$.

Overall, drug nanocrystals show several benefits over the micronized particles. However, the nanotoxicity of drug nanocrystals cannot be ignored because the nanoparticles can be taken up by endocytosis and provoke damage to single cells, especially for drug nanocrystals stabilized by nondegradable stabilizers with particle size below $100 \mathrm{~nm}$. Furthermore, the persistency of nanoparticles in the body after administration also increase the risk of toxicity. Usually, the drug nanocrystals present low toxicity risk, because they can have a particle size higher than $100 \mathrm{~nm}$ and they are also biodegradable (i.e., when the water is sufficient to ensure the dissolution) $[15,16]$. 


\subsubsection{Co-crystals}

Over the last 15 years, the production of pharmaceutical co-crystals has gained an increased attention to overcome the problems associated with the poorly-water soluble drugs, and more recently co-amorphous systems have also been produced $[39,40]$. By definition, co-crystals (also called multi-component crystals) are crystalline materials composed by two or more different components in a well-defined stoichiometric ratio [41]. These components are usually an active pharmaceutical ingredients (API) and a co-crystal former, which can be an excipient or another drug [42]. The physicochemical properties of the APIs and the bulk material properties can be modified, while maintaining their therapeutic activity [43]. The rationale for co-crystals design implicates the formation of supramolecular heterosynthons of functional groups, such as carboxylic acid-aromatic nitrogen, carboxylic acid-amide and alcohol-pyridine, which are bonded in a noncovalently way. In addition, co-crystals can be also formed via intermolecular interactions of homosynthons, including carboxylic acid-carboxylic acid and amide-amide synthons [39, 44-46]. However, the supramolecular heterosynthons are significantly more predominant compared to homosynthons and favor the formation of co-crystals, because the interactions between the molecules result in $\mathrm{H}-$ bonding and form thermodynamically stable co-crystals $[39,47]$. Thus, the co-crystallization can enhance the physicochemical properties of APIs, such as dissolution rate, intrinsic solubility, melting point, hygroscopicity, compressibility, bulk density and friability [39].

\section{Production Methods of Drug Nanocrystals}

The particle size reduction for the formulation of drugs with poor aqueous solubility involves nanosization techniques based on two different approaches: top-down and bottom-up techniques $[48,49]$. In the top-down methodologies, nanosized particles are produced by decreasing the particle size by mechanical erosion of the larger bulk drug powder into smaller sized particle in a 
liquid suspension, using milling or homogenization techniques, while the bottom-up technologies enable the controlled precipitation or crystallization from the molecular state to produce drug nanoparticles of desired size, using precipitation techniques (Figure 3) [14, 16, 50].

The majority of the commercial pharmaceutical products are most commonly produced using a topdown approach, such as milling, because these techniques allow the repeatability at a high level and the changes in scaling-up are considerably easy to perform $[17,50]$. In addition, the bottom-up processes need for solvent removal, and they are more difficult to control, as most of the poorly water-soluble drugs are poorly soluble not only in aqueous, but also in organic media [6]. The process yield can diverge according to the methodology applied to produce the drug nanocrystals. For example, using milling methods, the yield can be substantially high in the case of the a batch process, although some material can be lost on the surfaces of the beads and the vessel [17]. Several techniques can be utilized for co-crystallization, including an array of solid state, mechanochemical, and liquid assisted techniques. Furthermore, various innovative methodologies, such as freezedrying, microfluidics, and ultrasound-assisted co-crystallization have been potentially used in cocrystals synthesis [39]. The main advantages and disadvantages of top-down and bottom-up approaches to produce drug nanocrystals are summarized in Table 2, and they will be discussed in detail in the following subsections. 


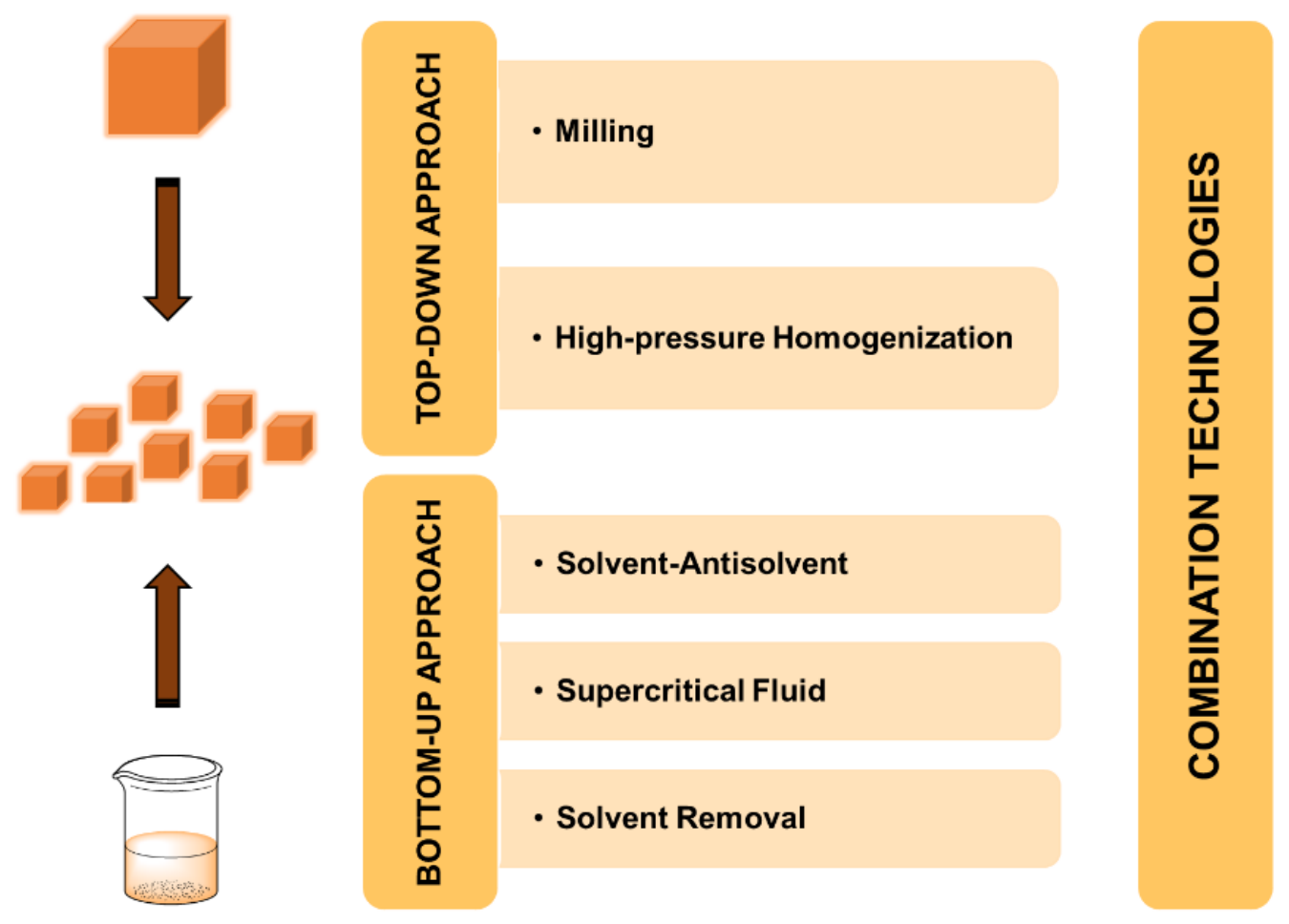

Figure 3. Schematic representation of the main methods for the production of drug nanocrystals, using top-down and bottom-up approaches.

Table 2. Summary of the general advantages and disadvantages of top-down and bottom-up approaches $[2,51]$.

\begin{tabular}{|c|c|c|}
\hline Methodology & Advantages & Disadvantages \\
\hline $\begin{array}{l}\text { Top-down } \\
\text { Approaches }\end{array}$ & $\begin{array}{l}\text { - Simple } \\
\text { - Fast } \\
\text { - Avoid organic solvents } \\
\text { - High reproducibility } \\
\text { - Easy of scale-up }\end{array}$ & $\begin{array}{l}\text { - Energy-intensive technique } \\
\text { - Potential instability of drugs induced by } \\
\text { high shear and temperature } \\
\text { - Product contamination from the grinding } \\
\text { media }\end{array}$ \\
\hline $\begin{array}{l}\text { Bottom-up } \\
\text { Approaches }\end{array}$ & $\begin{array}{l}\text { - Small particle size } \\
\text { - Monodispersed particles } \\
\text { - Cost-effective }\end{array}$ & $\begin{array}{l}\text { - Difficult to scale-up } \\
\text { - Time-consuming to find the suitable } \\
\text { conditions } \\
\text { - Difficult to control the particle growth } \\
\text { - Incomplete removal of toxic solvents }\end{array}$ \\
\hline
\end{tabular}


The combination of different particle size reduction technologies can also be employed to improve the particles size reduction, combining the effectiveness of the standard top-down and bottom-up techniques $[52,53]$. Generally, the first step consists of a precipitation approach (e.g., free-drying or spray drying) that modifies the drug structure to obtain a brittle and friable starting material for the subsequent homogenization process $[52,53]$. The main combination technologies that have been used are discussed in detail in section 3.

\subsection{Top-down Approach}

In the top-down approach, microsized drug crystals are submitted to a mechanical attrition or high pressure collisions that leads to the decrease in the particle size to the nanometer range. The main processes employed to achieve this are milling and high-pressure homogenization (HPH) [54]. The main advantages of these processes include the preparation of crystalline nanoparticles, flexibility in the scale-up production, and no harsh solvents [55]. However, these methods involve high energy input and are highly inefficient and time-consuming $[54,56]$. For example, using high pressure up to 1700 bar during the homogenization process, 50 to 100 cycles are still required to achieve the desired particle size and size distribution $[6,14]$. The milling time can also differ from hours to days, according to the properties of the drug, the milling media, and the extent of particle size reduction [57]. In addition, the contamination from the grinding media can lead to unexpected side effects, which can be a problem when the nanocrystals are considered for i.v. administration [54, $56]$.

The formation and physical stability of drug nanocrystal suspension can be affected by the manufacturing process, and consequently, alter the overall performance of drug nanocrystal suspensions [58, 59]. Heat sensitive drugs can be degraded by the heat generated in top-down methods [56]. Furthermore, the milling can cause crystal imperfections due to disordering of the crystal surface, and expose a hydrophobic surface with the decrease in the particle size. The 
rearrangement of crystals defects and re-crystallization of amorphous regions can lead to both physical and chemical instability of the resulting products during storage [60].

Industrially, the NanoCrystal ${ }^{\circledR}$ technology is the classical milling process to reduce the particle size. Regarding the high pressure homogenization methods, the crystals can be grounded using three different technologies: Microfluidizer technology (IDD-P ${ }^{\circledR}$ technology), Piston-gap homogenization in water (Dissocubes ${ }^{\circledR}$ technology) or in water mixtures/non-aqueous media (Nanopure ${ }^{\circledR}$ technology) $[15,16]$. Most of the nanocrystal products launched on the market are produced using the NanoCrystal technology for oral administration, as summarized in Table 3 [61]. Nanocrystals for oral administration are easier to prepare compared to the i.v. administration, and the drug nanocrystals are released from the tablets or suspensions [61].

Table 3. Examples of nanocrystal products on the market. Adapted with permission from ref. [62].

\begin{tabular}{|c|c|c|c|c|c|c|}
\hline Product & Drug Compound & Indication & $\begin{array}{l}\text { Administration } \\
\text { Route }\end{array}$ & $\begin{array}{l}\text { Nanosizing } \\
\text { Approach }\end{array}$ & $\begin{array}{l}\text { Pharma } \\
\text { Company }\end{array}$ & $\begin{array}{l}\text { Approval } \\
\text { Date }\end{array}$ \\
\hline Gris-Peg $\left.^{(}\right)$ & Griseofulvin & Anti-fungal & Oral & Precipitation & Novartis & 1982 \\
\hline Cesamet $^{\circledR}$ & Nabilone & Anti-emetic & Oral & Precipitation & Lilly & 2005 \\
\hline $\begin{array}{l}\text { Verelan } \\
\text { PM }^{\circledR}\end{array}$ & Verapamil & $\begin{array}{l}\text { Anti- } \\
\text { arrhythmia }\end{array}$ & Oral & Media Milling & Schwarz & 1998 \\
\hline $\begin{array}{l}\text { Rapamune } \\
\text { (®) }\end{array}$ & Sirolimus & Immuno- & Oral & Media Milling & Wyeth & 2000 \\
\hline $\begin{array}{l}\text { Focalin } \\
\mathrm{XR}^{\circledR}\end{array}$ & $\begin{array}{l}\text { Dexmethylphenida } \\
\text { te hydrochloride }\end{array}$ & $\begin{array}{l}\text { Anti- } \\
\text { psychotic }\end{array}$ & Oral & Media Milling & Novartis & 2001 \\
\hline Avinza ${ }^{\circledR}$ & Morphine sulfate & $\begin{array}{l}\text { Anti- chronic } \\
\text { pain }\end{array}$ & Oral & Media Milling & King Pharm & 2002 \\
\hline $\begin{array}{l}\text { Ritalin } \\
\text { LA }^{\circledR}\end{array}$ & $\begin{array}{l}\text { Methylphenidate } \\
\text { hydrochloride }\end{array}$ & $\begin{array}{l}\text { Anti- } \\
\text { psychotic }\end{array}$ & Oral & Media Milling & Novartis & 2002 \\
\hline $\begin{array}{l}\text { Herbesser } \\
\text { (B) }\end{array}$ & Diltiazem & Anti-angina & Oral & Media Milling & $\begin{array}{l}\text { Mitsubishi } \\
\text { Tanabe } \\
\text { Pharma }\end{array}$ & 2002 \\
\hline $\begin{array}{l}\text { Zanaflex } \\
\text { тм }\end{array}$ & $\begin{array}{l}\text { Tizanidine } \\
\text { hydrochloride }\end{array}$ & $\begin{array}{l}\text { Muscle } \\
\text { relaxant }\end{array}$ & Oral & Media Milling & Acorda & 2002 \\
\hline Emend $^{\circledR}$ & Aprepitant & Anti-emetic & Oral & Media Milling & Merck & 2003 \\
\hline Tricor $^{\circledR}$ & Fenofibrate & Hypercholeste & Oral & Media Milling & Abbott & 2004 \\
\hline
\end{tabular}




\begin{tabular}{|c|c|c|c|c|c|c|}
\hline & & rolemia & & & & \\
\hline $\begin{array}{l}\text { Megace }^{\circledR} \\
\text { ES }\end{array}$ & Megestrol acetate & $\begin{array}{l}\text { Appetite } \\
\text { stimulant }\end{array}$ & Oral & Media Milling & Par Pharma & 2005 \\
\hline Naprelan $^{\circledR}$ & Naproxen sodium & $\begin{array}{l}\text { Anti- } \\
\text { inflammation }\end{array}$ & Oral & Media Milling & Wyeth & 2006 \\
\hline Theodur $^{\circledR}$ & Theophylline & $\begin{array}{l}\text { Bronchial } \\
\text { dilation }\end{array}$ & Oral & Media Milling & $\begin{array}{l}\text { Mitsubishi } \\
\text { Tanabe }\end{array}$ & 2008 \\
\hline Tridlide $^{\circledR}$ & Fenofibrate & $\begin{array}{l}\text { Hypercholeste } \\
\text { rolemia }\end{array}$ & Oral & $\begin{array}{l}\text { High Pressure } \\
\text { Homogenizati }\end{array}$ & $\begin{array}{l}\text { Pharma } \\
\text { Skye } \\
\text { Pharma }\end{array}$ & 2005 \\
\hline $\begin{array}{l}\text { Invega } \\
\text { Sustenna }\end{array}$ & $\begin{array}{l}\text { Paliperidone } \\
\text { palmitate }\end{array}$ & $\begin{array}{l}\text { Anti- } \\
\text { depressant }\end{array}$ & Injection & $\begin{array}{l}\text { High Pressure } \\
\text { Homogenizati } \\
\text { on }\end{array}$ & $\begin{array}{l}\text { Johnson \& } \\
\text { Johnson }\end{array}$ & 2009 \\
\hline
\end{tabular}

\subsubsection{Wet Media Milling}

As the dry milling (e.g., jet milling) is not effective on reducing the particle size to the nanometer range, the wet media milling process can be applied. In wet media milling, also known as pearl milling or bead milling, the drug particles are dispersed in a surfactant/stabilizer solution and this macrosuspension is exposed to milling energy to produce ultrafine particle suspension [16]. The low energy pearl milling was initially developed by Liversidge et al. in 1991, leading to the NanoCrystals ${ }^{\circledR}$ technology to achieve the particle size reduction [63]. Currently, NanoCrystal ${ }^{\circledR}$ technology is based on a high energy milling process to make this procedure more desirable for industrial pharmaceutical applications [64]. For that, the milling equipment needs to be sufficiently powerful to improve the process [65]. Using this method, high shear pearl mill consisting of milling chamber, milling pearls, milling motor, and a recirculation chamber is needed to produce the nanocrystal suspension (Figure 4).

First, the suspension containing the drug, water and surfactants is charged into the milling chamber along with the milling pearls, and then rotated at a high rate driven by the motor while the drug crystals are being nanosized between the moving pearls by the high shear forces. Generally, the drug concentration can range from 1 to $400 \mathrm{mg} / \mathrm{ml}$, the amount of drug in the milling chamber 
ranges can vary between 2 and $30 \mathrm{wt}-\%$ [49,57,66], and the weight ratio of drug to stabilizer ranges from 2:1 to 20:1 [65]. The mills can be containers with small pearls, beads, or balls presenting different sizes, typically between 0.2 and $1 \mathrm{~mm}$, and they can be made of different materials such as glass, zircon oxide, or polystyrene resin $[2,15,67]$. In this regard, the polystyrene resin beads might provide a better option to reduce the contamination caused by erosion from the mills into the drug formulation [18]. Usually, the number per volume of the milling pearls per beads can range between 10 to $50 \%$ of the weight per volume of the slurry [57]. Fine nanocrystal suspension can be obtained after minutes to several days and up to a week, according to a variety of parameters, including the drug hardness, viscosity, temperature, energy input, size of the milling media, surfactant concentration used and administration route of the particle [61]. For example, nanocrystals can be obtained either by low milling speeds $(80-90 \mathrm{rpm})$ and long milling times (1-5 days) or using high milling speeds (1800-4800 rpm) and short milling times (30-60 min) [57, 6871]. The progress can be performed in either batch, recirculation or continuous mode, with a very small batch-to-batch variation to obtain a narrow particle size distribution [2]. The batch mode is mainly used to the develop drug nanocrystal suspensions at the laboratory scale [4]. In the recirculation mode, the milling set-up is constituted by a recirculation pump and a holding tank, in which the pump allow the suspension to flow from the holding tank through the mill, and go back into the holding tank. This approach permits the production of a fixed batch size that is limited by the capacity of the holding tank. Nanocrystal ${ }^{\circledR}$ Technology uses the recirculation media milling to produce drug nanocrystal suspensions in the marketed products $[4,72]$. In addition, two types of continuous mode (multipass continuous and the cascade-continuous mode) can be used, where a receiving tank allows the continuous withdrawal of product from the mill. In the continuous modes, the suspension circulates from the holding tank through the mills, and finally goes into the receiving tank [72]. The continuous processing mode is widely used for large-scale production and the 
pharmaceutical manufacturing sector is interested to move from batch processes to the continuous processes $[4,72]$.

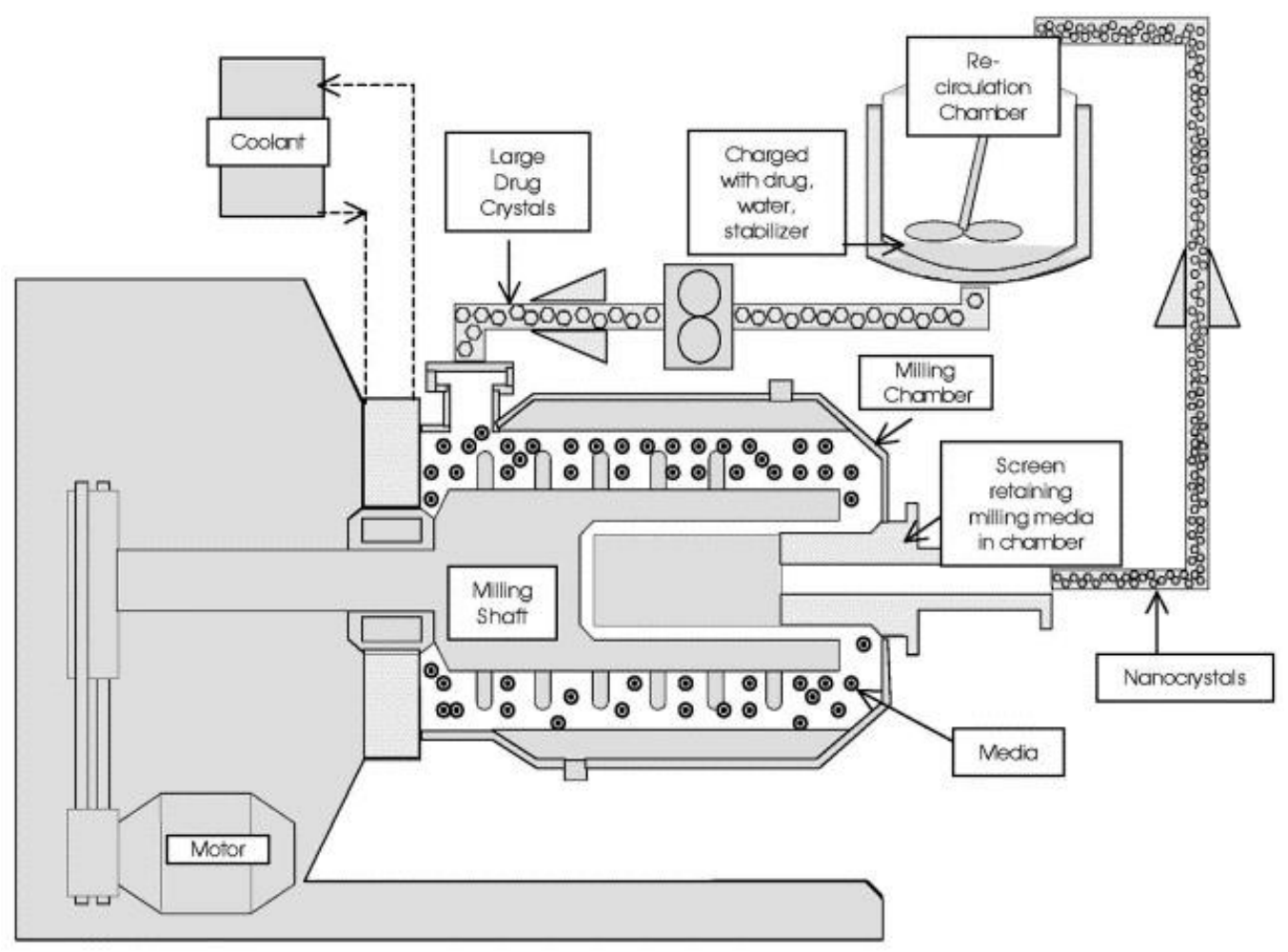

Figure 4. Schematic representation of the media milling process. The media containing drug, water and stabilizer is charged in the milling chamber and processed into a nanocrystalline dispersion. The mill can be operated in a batch or re-circulation mode. Typically, the residence time necessary to produce nanometer-sized dispersion with a mean diameter $<200 \mathrm{~nm}$ is $30-60 \mathrm{~min}$. Reproduced with permission from ref. [49], (C) 2003, Elsevier B.V.

The main advantages of the milling process are their large-scale production and the simple and lowcost technology regarding the milling itself. However, this process also present some disadvantages, such as: (i) the potential erosion from the mills leading to the product contamination; (ii) the growth of microorganisms in the water phase can occur when the milling time is too long and the progress is performed at room temperature; (iii) the process can be time-consuming; and (iv) the time and costs related to the separation procedure of the milling material from the drug nanoparticle suspension can increase, especially when considering the production of parenteral sterile products 
[73]. Process parameters like bead size/material, stirring speed and energy input can also affect the level of contamination. Using the same bead material, the level of contamination can be minimized by shortening the process time and lowering the bead contact pressure by using smaller bead sizes [17]. In addition, amorphization or variations in the physical form of the drug can also occur during the milling process $[74,75]$. The lattice vibrations can increase when the mechanical pressure rise above specific critical pressure values, destabilizing the crystal lattice. Consequently, the transformation into an amorphous state occurs when the number of defects on the crystal is too high, where the amorphous state is more stable than the destabilized crystals $[57,76]$. Although the improvement on the drug dissolution, the formation of amorphous regions in nanocrystals is often undesirable due to their poor stability [76]. Thus, the formation of amorphous regions during the milling process is closely related to the process parameters and the properties of the individual drug and stabilizer, as well as the possible interactions between them. However, water in the wet milling of crystalline drugs can act as an inhibitor of the formation of amorphous material due to the reduced glass-transition temperature [74].

NanoCrystal $^{\circledR}$ technology have been widely used to produce drug nanocrystals mainly for oral administration, as shown in Table 3. These products have been formulated either as liquid oral dosage forms (suspensions) or as solid oral dosage forms (tablets and capsules). A solidification step is required after the preparation of drug nanocrystal suspensions to formulate solid oral dosage forms. For this, the drying process can be performed using spray and freeze drying techniques, as well as fluidized-bed coating, granulation, and pelletization that can yield formulations with more straightforward downstream processing to tablets or capsules [77]. Furthermore, the addition of matrix formers like sugars can be done to produce solid nanocrystalline particles that are able to redisperse upon rehydration and enhance their clinical performance [4, 78].

Rapamune $^{\circledR}$, an immunosuppressive drug (Sirolimus), was the first product using a pure drug nanoparticle platform to reach the market, and is available as oral tablets [6]. This product was 
developed using NanoCrystal ${ }^{\circledR}$ technology to overcome the limitations of the first commercially available lipid-based liquid solution of rapamycin. This formulation required cold storage and protection from light, had a complicated dispensing protocol and the taste was unpalatable [4, 65]. When processed using wet milling technology, a fine nanoparticle dispersion of rapamycin was produced, with a mean particle size lower than $200 \mathrm{~nm}$. The NanoCrystal Colloidal Dispersion ${ }^{\circledR}$ intermediate was then post-processed into tablets of 1,2 and $5 \mathrm{mg}$ potency, which exhibited ca. $27 \%$ increased bioavailability of the drug compared to the lipid-based solution, no restrictive storage conditions, and they are easy to administrate where needed, enhancing the patient compliance $[4,65,79]$.

The second product developed using NanoCrystal ${ }^{\circledR}$ technology was Emend ${ }^{\circledR}$, a poorly-water soluble antiemetic drug aprepitant, formulated as capsules that contain sugar beads coated with an aprepitant drug nanocrystal suspension [80]. The free base crystalline compound was first processed into a fine particle dispersion using a wet milling technology, followed by processing into a solid dosage capsule formulation. This formulation allowed to eliminate the high fasted/fed state variation compared to the conventional dosage form and improve the drug bioavailability, providing a more elegant dosage form $[4,65]$.

Overall, the wet ball milling is a versatile technology that allow to process almost any API, opening the possibility to use this technology as a platform to formulate poorly water-soluble drug compounds. During the past years, different studies reported the preparation of particle sizes ranging between 100 and $300 \mathrm{~nm}$ (Table 4), showing the universal applicability of this particle size reduction method [81].

Table 4. Examples in the literature of drug nanocrystals prepared by wet milling methods.

\begin{tabular}{lllll}
\hline Drug Compound & Indication & Particle size (nm) & $\begin{array}{l}\text { Administration } \\
\text { Route }\end{array}$ & Reference \\
\hline Itraconazole & Anti-fungal & 128 & Intravenous & {$[82]$}
\end{tabular}




\begin{tabular}{|c|c|c|c|c|}
\hline $\begin{array}{l}\text { Itraconazole:maleic } \\
\text { acid } 2: 1 \text { co crystal }\end{array}$ & Anti-fungal & - & - & [83] \\
\hline Candesartan cilexetil & Hypertension & 128 & Oral & [84] \\
\hline Loviride & Anti-HIV agent & 264 & - & [71] \\
\hline Ketoconazole & Anti-fungal & 254 & Oral & [85] \\
\hline Cyclosporine & Immunosuppressant & 213 & Intravenous & [86] \\
\hline Cilostazol & $\begin{array}{l}\text { Antiplatelet, } \\
\text { antithrombotic and } \\
\text { vasodilating }\end{array}$ & 222 & Oral & [87] \\
\hline Hydrocortisone & $\begin{array}{l}\text { Inflammation } \\
\text { disorders }\end{array}$ & 300 & Ophthalmic & [88] \\
\hline 1,3-Dicyclohexylurea & Hypertension & 800 & Subcutaneous & [89] \\
\hline Niclosamide & $\begin{array}{l}\text { Anthelmintic, } \\
\text { anticancer }\end{array}$ & $<300$ & avenous & [90] \\
\hline Indomethacin & Anti-inflammatory & $<400$ & & [91] \\
\hline
\end{tabular}

\subsubsection{High-Pressure Homogenization}

High-pressure homogenization is another technology that has been applied to reduce the particle size of poorly water-soluble drug molecules. According to the homogenization equipment and the homogenization parameters, high-pressure homogenization can be divided into three basic processes: (i) Microfluidizer technology (IDD-PTM technology) based on the jet stream principle; (ii) piston-gap homogenization either in water (Dissocubes ${ }^{\circledR}$ Technology); or (iii) in mixtures of water with water-miscible liquids (Nanopure ${ }^{\circledR}$ Technology) [2, 61].

The Canadian company RTP developed the Microfluidizer technology, also called Insoluble Drug Delivery-Particles (IDD-PTM) technology, using a jet stream homogenizer [15]. Here, the API is suspended in a dispersion media (usually water), and the small particles are generated by a frontal collision of two high energy fluid streams in a chamber under pressure up to 1700 bar, leading to the particle collision, shear forces and cavitation forces (Figure 5A) [15, 16, 92]. This technique can use two different types of interaction chamber: Z-type and Y-type (Figure 5B). In the Z-type chamber, the direction of the suspension flow changes a few times, which leads to the particle 
collision and shear forces, while in the Y-type, the suspension stream is divided into two streams that will frontally collide [14]. The Z-type chambers are typically used for solid dispersions, while the Y-type chambers are commonly used to prepare liquid-liquid types of dispersions such as emulsions and liposomes [92]. Surfactants can also be added to the solution to stabilize the prepared particles. The desired size of particles can be obtained after high number of cycles that can range from 50 to even 100 passages, representing a disadvantage of this method [14, 61]. In addition, the obtained product can also be composed by a relatively large fraction of microparticles, losing the benefits of a real homogeneous drug nanocrystal suspension [14].

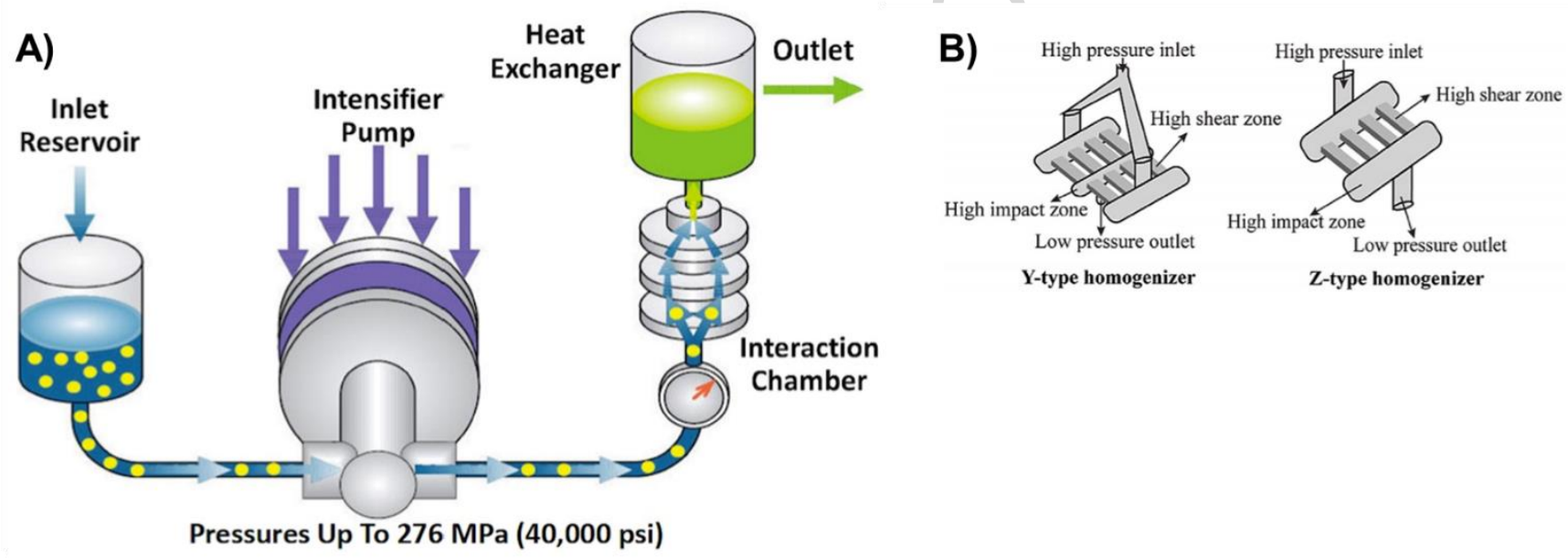

Figure 5. Schematic representation of the Microfluidizer Technology: (A) Setup utilized for nanocrystal production and (B) Types of homogenization chamber (Z- or Y-type), adapted with permission from (A) ref. [92], (C) 2015, Microfluidics International Company and (B) ref. [54], (C) 2016, Elsevier B.V.

The Dissocubes ${ }^{\circledR}$ technology uses piston-gap homogenizers to produce nanoparticle suspensions in water at room temperature. The particles are formed as a consequence of particle collision, shear and gravitation forces. In this case, the API, dispersed in an aqueous or non-aqueous surfactant solution, is forced by a piston to pass through the tiny homogenization gap, under pressure that can go up to 4000 bar, but usually varies between 1500 and 2000 bar (Figure 6) [6]. Consequently, the 
high streaming velocity of the suspension origins an increased the dynamic pressure $(q)$, which is compensated by a reduction in the static pressure $(p)$ below the vapor pressure of the aqueous phase, according to Bernoulli's law (Eq. 4), where $p_{0}$ is total pressure:

$$
p_{0}=p+q
$$

The reduction of particle size is a result of the lower pressure inside the piston-gap homogenizer than the atmospheric pressure, leading to the boiling of the solvents at room temperature. When the liquid leaves the homogenization gap, the formed gas bubbles implode immediately due to the sudden increase in pressure to 1 bar, leading to cavitation and particle collision $[16,18]$. The mean size of the obtained particles will depend on the homogenizer pressure, number of homogenization cycles, and hardness of the drug [61]. However, the use of water can cause the hydrolysis of watersensitive drugs and some other issues related to the subsequent drying steps [16]. In addition, temperature is another important parameter that needs to be controlled, especially when the drug is temperature sensitive [2].

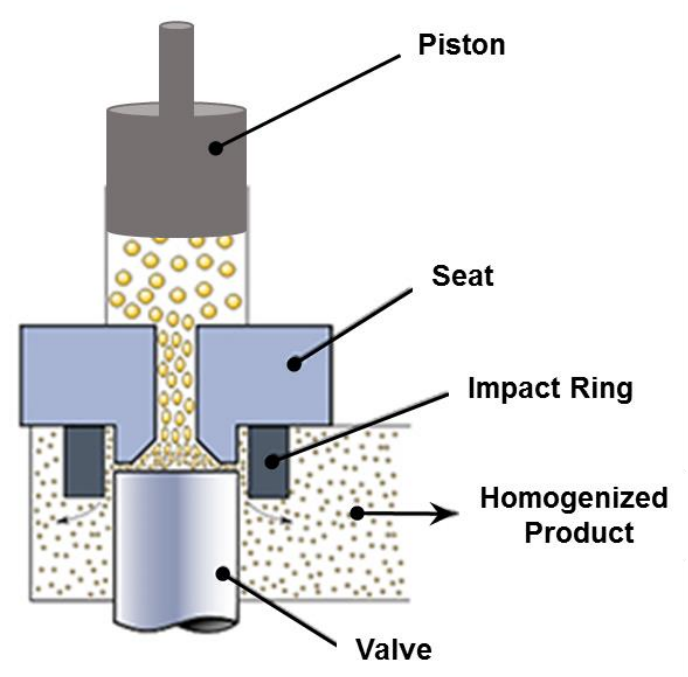

Figure 6. Schematic representation of high pressure homogenization using a piston gap homogenizer. Adapted with permission from ref. [93] @ 2018, Dairy Engineering Company.

A development of this method using the piston-gap homogenizer is the Nanopure ${ }^{\circledR}$ technology, which uses water-free media (e.g., oils, PEGs) or water-reduced media (e.g., glycerol/water 
mixtures for the production of isotonic formulations) dispersion media, with a low vapor pressure and low temperatures for the homogenization [16, 61]. In this case, the cavitation in the homogenization gap is reduced or practically inexistent, as a consequence of the low-vapor pressure and low temperatures $\left(e . g ., 0^{\circ} \mathrm{C}\right)$ used during the homogenization process. The turbulent flow and shear forces are strong enough to reduce the drug particles to nanocrystals. In addition, the HPH in non-aqueous or water-reduced media is particularly beneficial if the drug nanocrystal suspension has to be transferred into a traditional final dosage form. For example, the oil dispersions can directly be filled into gelatin capsules for oral administration, or injected parenterally as controlled drug delivery depot. Furthermore, when the water content in the dispersion medium is reduced, the required energy is minimized for drying steps (e.g., spray-drying or fluidized bed drying). Moreover, the production of drug nanocrystal suspensions at $0{ }^{\circ} \mathrm{C}$ or even below can prevent temperature labile drugs from degradation $[16,61,94]$.

Homogenization methods are low-cost and simple techniques already approved for the production of different pharmaceutical products, as well as in the cosmetics and food industry. In addition, the process can be easily converted from the lab-scale to the large production scale [95]. When the procedure is optimized after adjustment of the production parameters, high quality drug nanocrystal suspensions with little batch-to-batch variation can be achieved [16]. Although high pressure homogenizers consist mainly of steel parts, the impurity levels found in drug nanocrystal suspensions prepared via HPH processes are considerably lower than using wet milling. However, the abrasion and wearing of HPH equipment can happen when extremely hard material is processed in piston-gap homogenizers, leading to a reduction in process efficiency. For this reason, the homogenization valves have been recently equipped with ceramic tips, which can withstand harsh process conditions, to decrease the risk of contamination $[81,96]$. 
There are several examples in the literature using HPH to produce drug nanocrystal suspensions, as shown in Table 5. However, the particle size reduction seems to be less effective than wet milling, which can be due to the physicochemical properties of drug molecules.

Table 5. Examples in the literature of drug nanocrystals prepared by $\mathrm{HPH}$.

\begin{tabular}{lllll}
\hline Drug Compound & Indication & Particle size (nm) & Administration Route & Reference \\
\hline PX-18 & Phospholipase A2 & 50 & & {$[97]$} \\
& inhibitor & & Intravenous & {$[98]$} \\
Asulacrine & Topoisomerase II & 133 & & \\
& inhibitor & & Topical & {$[99]$} \\
Resveratrol & Anti-oxidant & $150-200$ & - & {$[100]$} \\
Celecoxib & COX-2 inhibitor & $130-1840$ & Oral & {$[101]$} \\
Azithromycin & Antibacterial & 400 & Intravenous & {$[102]$} \\
Spironolactone & Diuretic & 400 & Intravenous & {$[94]$} \\
Omeprazole & Proton pump inhibitor & 600 & - & {$[103]$} \\
Hydrocortisone & Glucocorticoid drug & 539 & Intravenous & {$[104]$} \\
Nimodipine & Hypertension & 650 & Oral & {$[105]$} \\
Rutin & Anti-oxidant & $547-912$ & - & {$[106]$} \\
Oridonin & Antitumoral & 912 & - & {$[107]$} \\
Diclofenac & Nonsteroidal anti- & $<800$ & & \\
& inflammatory & & & \\
\hline
\end{tabular}

\subsection{Bottom-up methods}

The bottom-up methods for the production of drug nanocrystals rely on the controlled precipitation of the drug molecules into nanocrystals [48, 108]. The most widely investigated production methods are solvent-antisolvent precipitation (both conventional in bulk and with the aid of microfluidics), the precipitation in supercritical fluids, solvent evaporation (spray dryer), and a decrease in the temperature (freeze dryer) [109, 110].

\subsubsection{Solvent-antisolvent}


The principle underlying the production of drug nanocrystals by solvent-antisolvent precipitation relies on the intensive mixing of a drug solution in organic solvent (miscible with water) into an antisolvent (usually water or other aqueous media), forming the supersaturation conditions in the aqueous phase that leads to the nucleation and the precipitation of drug molecules, and finally forming the nanosized drug nanocrystals $[108,111,112]$. The nucleation process proceeds along a change in the free energy $\left(\Delta \mathrm{G}_{\text {cryst }}\right)$ of the system which depends on the size of the crystal: thereby, for the nucleation process to occur, an energy barrier needs to be overcome [113]. The critical size leading to the formation of crystal nuclei is dependent on both supersaturation conditions and temperature [113]. Moreover, organic molecules can crystallize also following a non-classical pathway, where nanometer size particles forms superstructures when in presence of stabilizers, according to the mechanisms hypothesized in Figure 7, due to interactions between the surfactant molecules on the surface of the newly formed nanocrystal. [114]. 


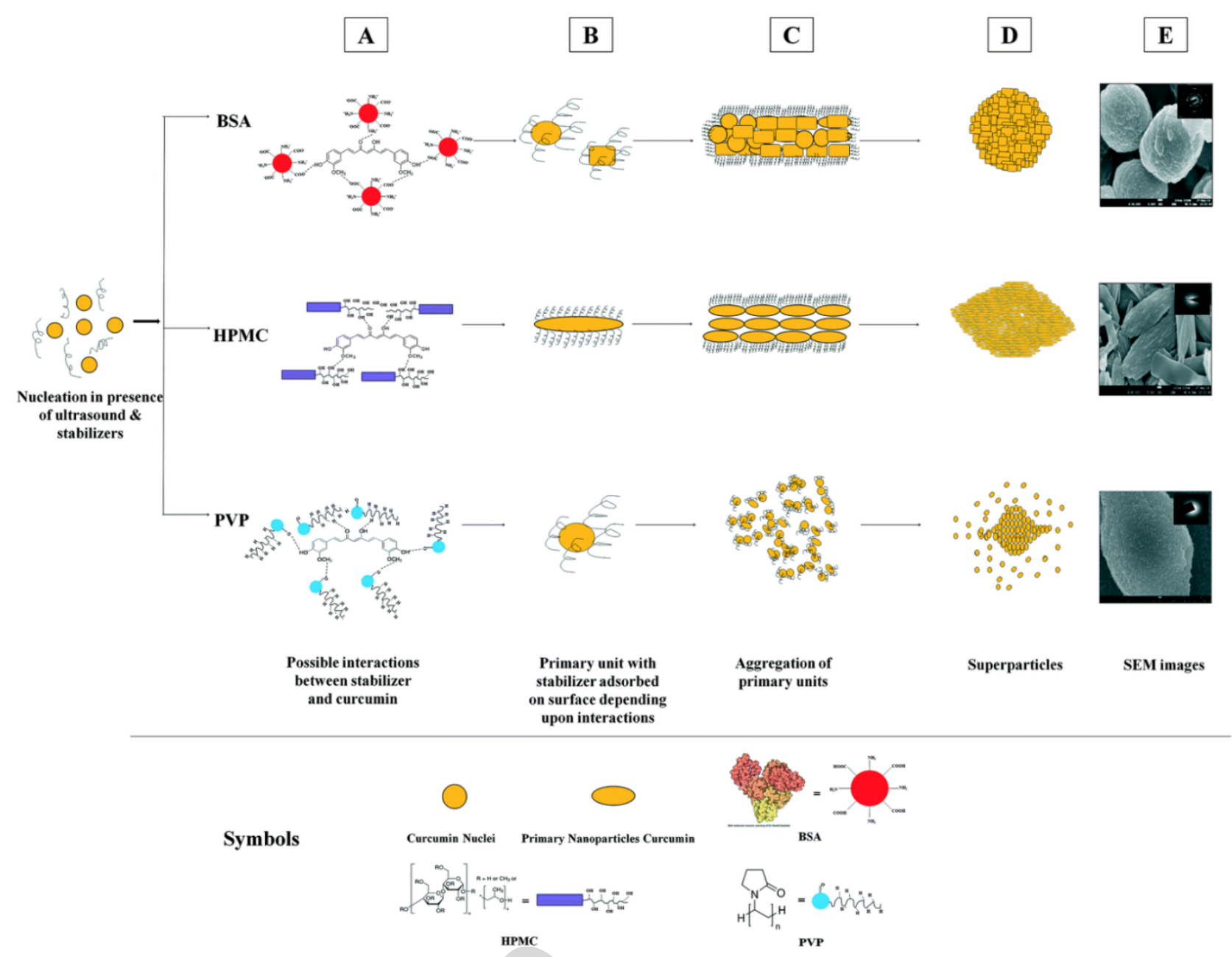

Figure 7. Process of formation of curcumin nanocrystal superstructures in presence of different stabilizers. (A) Interaction between primary curcumin crystal and stabilizer. (B) Morphology of the primary unit according to the interactions between crystal and stabilizer. (C) Aggregation of multiple primary structures. (D) Superparticles formed by primary units. (E) Scanning Electron Microscope (SEM) micrographs of the curcumin superstructures. Reproduced with permission from ref. [114], (C) 2014, Royal Society of Chemistry.

\subsubsection{Conventional methods}

As for the conventional method for the preparation of drug nanocrystals, Matteucci et al. evaluated the effect of variables on the particle size of itraconazole crystals formed by precipitation of the drug molecules in an ethanol:water system, in presence of a stabilizer (poloxamer 407) [115]. The 
variables investigated included the mixing/precipitation time, concentration of drugs, volume ratio between the organic and aqueous phases, concentration and location of the surfactant (aqueous or organic phase), intensity/speed of mixing/stirring, injection rate of the organic solutions in the aqueous [115-117]. The drug concentration is inversely correlated to the size of the particles for intense mixing conditions: more concentrated drug solution will result into higher supersaturation in the aqueous phase, with the formation of a higher number of nuclei with smaller final size [116]. Moreover, the choice of the stabilizer influences the nanocrystals size, the use of hydrophobin allowed the production of beclomethasone propionate crystals presenting a size around $100 \mathrm{~nm}$, and the stabilizer also increased the stability of the crystals both in solution and after freeze drying [118]. Homayouni et al. compared the properties of celocoxib crystals produced either by antisolvent precipitation or by HPH, with PVP as stabilizer. The celecoxib crystals produced by different techniques showed different morphology (spherical for precipitation and irregular shape for the other ones), different dissolution profiles (higher for the samples processed with HPH), and different particle size (the crystals precipitated and spray dried formed microsize particles, while both the samples precipitated and freeze dried and the ones processed by HPH formed nanocrystals in the range between 200 and $800 \mathrm{~nm}$ ) [119].

The precipitation of the nanocrystals can be helped by static mixing. The first two nanoprecipitation techniques introduced at industrial level are the preparation of hydrosols (patent owned by Novartis) and NanoMorph ${ }^{\circledR}$ (Soliqs) [6]. In the case of NanoMorph ${ }^{\circledR}$, amorphous drug nanoparticles can be prepared by producing a heated drug organic solvent solution, to increase the supersaturation, followed by the mixing with cooled antisolvent for a rapid nucleation [109].

As for the production of co-crystals, the drugs can be dissolved into different miscible organic solvents, premixed, and then added to aqueous solution to result into saturated drugs solutions with the controlled precipitation of the paired drug molecules [120, 121]. The precipitation conditions can be predicted by analyzing the phase solubility diagrams: micrococrystals of saccharin and 
indomethacin were prepared by adding water to drug-cofomer solutions in different organic solvents, to evaluate the effect of the solvent characteristics on the precipitation process [122]. The yield is quite high, with a recovery of $70-80 \%$ [123]. The yield was further augmented by introducing cooling into the system: the timing of the cooling influenced the formation of the cocrystals. The metastable $\alpha$-indomethacin formed only when the cooling was applied before the nucleation [124].

A further reduction in the particles size of the crystals may be achieved by performing the precipitation together with other external factors. In ultrasound assisted antisolvent precipitation, ultrasounds (either from a bath or from a probe sonicator) are introduced in the solution containing the drug molecules, leading to an improved supersaturation thanks to the intense mixing inherent to the cavitation phenomenon $[125,126]$. This technique is useful to prepare aceclofenac nanocrystals with average size around $112 \mathrm{~nm}$, and a low polydispersity index (PdI) (0.165). The obtained crystals assessed both in vitro and in vivo, showed a great enhancement of the dissolution rate and an increase in the drug bioavailability [127]. The size of the crystals depend on the parameters of the sonication, such as the probe sonicator, the intensity and time of the sonication, the length of the probe, the position of the probe within the liquid, and the cavitation induced by the sonicator [109]. Xia et al. produced nifedipine nanocrystals by precipitation coupled with ultrasonication [128]. The effect of the energy input and of the length of the sonication on the particle size has been studied. The nanocrystals with an average particle size of $209 \mathrm{~nm}$ formed without any major change in the crystalline status. A comparison between the bottom-up and top-down approaches was performed by Soliman et al [129]. They prepared nanocrystals of avanafil by sono-assisted precipitation, and investigated the effect of different stabilizers on the particle size. The properties of the crystals were compared to formulations prepared by precipitation followed by $\mathrm{HPH}$, highlighting the effect of the types of the stabilizers and the challenges in obtaining stable suspensions. Ultrasounds were employed in the formulation of co-crystals [121]. Interestingly, the use of this technique may also 
enable the formation of co-crystals between substances that are non-congruently soluble. For example, in a system containing caffeine/maleic acid, a 2:1 co-crystal was obtained after ultrasound assisted solution crystallization [130].

High gravity controlled precipitation (or Higee) exploits a rotating packing bed on earth to enhance the mixing process $[109,131]$. This technique was used for the production of drug nanocrystals of cephradine, with an average size between 200 and $400 \mathrm{~nm}$, without any major change in the crystalline status [132]. High gravity antisolvent precipitation utilizes the same technique to prepare amorphous drug nanoparticles, e.g., ceforoxim axetil, danazol and salbutamol, in a solvent-free fashion [133-135].

Johnson and Prud'homme established the flash nanoprecipitation (FNP) technique that allows the control of the thermodynamic and kinetic conditions of the process to promote the particles nucleation, using a mixing time in this process on the order of milliseconds, rendering stable and controlled-size nanoparticles [136]. This process offers the local supersaturation conditions required for particle nucleation, via fast mixing in the turbulent regime in a confined volume of a stream containing the dissolved solute and stabilizer with an opposite stream that contains a miscible solvent, acting as a non-solvent for simultaneously precipitation of the solute and stabilizing molecule. Here, the block copolymer prevents further growth of the drug particles, and it can also provide steric stabilization due to the hydrophilic block on the surface of the particle.[137] Using FNP, Bteich et al. fabricated Cellax polymeric conjugates, composed by carboxymethyl cellulose functionalized with PEG and cabazitaxel, an anticancer drug [138]. Different parameters, including concentration, mixing rate, solvent ratios and subsequent dilution, were tested to produce nanoparticles with an average size of $60 \mathrm{~nm}$.

Another technique, evaporative precipitation in an aqueous solvent (EPAS) requires the heating of the drug molecules in organic solvent above the solvent boiling point. This organic solvent solution is then sprayed into the aqueous phase [139, 140]. 
Examples of nanocrystals and nano co-crystals produced by conventional antisolvent precipitation can be found in Table 6.

Table 6. Drug nanocrystals prepared according to the conventional antisolvent processes.

\begin{tabular}{|c|c|c|c|c|}
\hline Technique & Drug & Outcome & Year & Reference \\
\hline \multirow[t]{3}{*}{$\begin{array}{l}\text { Solvent-antisolvent } \\
\text { precipitation }\end{array}$} & Itraconazole & $\begin{array}{l}\text { Nanocrystals, } \\
<300 \mathrm{~nm}\end{array}$ & 2006 & [115] \\
\hline & $\begin{array}{l}\text { Beclomethasone } \\
\text { Propionate }\end{array}$ & $\begin{array}{l}\text { Nanocrystals, } \\
<100 \mathrm{~nm}\end{array}$ & 2010 & {$[118]$} \\
\hline & Celocoxib & $\begin{array}{l}\text { Nanocrystals, 291- } \\
442 \mathrm{~nm}\end{array}$ & 2014 & [119] \\
\hline \multirow[t]{3}{*}{ Sonoprecipitation } & Aceclofenac & $\begin{array}{l}\text { Nanocrystals, } 112 \\
\text { nm, PdI } 0.1655\end{array}$ & 2017 & [127] \\
\hline & Nifedipine & $\begin{array}{l}\text { Nanocrystals, } 209 \\
\text { nm }\end{array}$ & 2010 & {$[128]$} \\
\hline & Caffein:Ma & $\begin{array}{l}\text { Comparison } \\
\text { between top-down } \\
\text { and bottom-up } \\
\text { approaches, } \\
128-4868 \mathrm{~nm} \\
\text { Formation of a co- } \\
\text { crystals from } \\
\text { substances non } \\
\text { congruently } \\
\text { soluble }\end{array}$ & 2010 & [130] \\
\hline $\begin{array}{l}\text { High Gravity } \\
\text { Controlled } \\
\text { Precipitation }\end{array}$ & Cephradine & $\begin{array}{l}\text { Nanocrystals, } \\
200-400 \mathrm{~nm}\end{array}$ & 2005 & {$[132]$} \\
\hline $\begin{array}{l}\text { High Gravity } \\
\text { Antisolvent }\end{array}$ & Cefurozime axetil & $\begin{array}{l}\text { Amorphous } \\
\text { nanoparticles, } 300\end{array}$ & 2006 & {$[133]$} \\
\hline \multirow[t]{2}{*}{ Precipitation } & & $\mathrm{nm}$ & & \\
\hline & Danazol & $\begin{array}{l}\text { Nanocrystals, } 190 \\
\text { nm }\end{array}$ & 2009 & {$[134]$} \\
\hline Evaporative & Itraconazole & Higher dissolution & 2005 & {$[140]$} \\
\hline
\end{tabular}




\subsubsection{Microfluidics}

Microfluidics is a technique that manipulates small amount of fluids ( $10^{-9}$ to $10^{-18}$ litres) within channels presenting dimensions in the tens of micrometres [141, 142]. This technique has attracted increasing attention as a new method to prepare drug nanocrystals in the past few years due to its advantages (accurate manipulation of the fluids and customizable microscale channels). Moreover, this technique has been widely explored for the preparation of nanoparticles and composite nanoplatforms for a variety of applications, such as chemotherapy, cancer immunotherapy, treatment of liver failure, delivery of macromolecules in diabetes, enhancement of dissolution rate of poorly water-soluble drug molecules.[143-163] Comparing with the conventional production methods, microfluidics displays many advantages. The small spaces and large surface area-to-volume ratio in the microfluidics channels result in a reduced mixing path (tens of micrometers) and in a short mixing time (millisecond to microsecond) [157]. Thereby, drug nanocrystals prepared through microfluidics tend to have smaller size and narrower size distribution because of the fast mixing process and quick precipitation [164, 165]. Moreover, the size of the drug nanocrystals is tunable by modifying the flow rate of the solution, the solvent and antisolvent, the concentration of the drug, and the device configuration [166]. Furthermore, microfluidics can advantageously present lower batch-to-batch variation due to the continuous flow [167], and thus, represents a more cost-effective way to prepare drug nanocrystals compared to the bulk conventional methods.

The variables involved in the microfluidics precipitation of drug nanocrystals can be described by various parameters. Reynolds number $(\mathrm{Re})$ is an important dimensionless parameter that 
describes the flow characteristics of the fluid in the channels [168]. Re can be calculated by the following equation (Eq. 5):

$$
\operatorname{Re}=\frac{\rho v \mathrm{~L}}{\eta}
$$

where, $\rho$ is the density of the fluid, $v$ is the velocity vector of the fluid, $L$ is the characteristic length, and $\eta$ is the dynamic shear viscosity [168]. A laminar flow, which is characterized by distinct streamlines, usually appears when Re is lower than 1800 [157]. Contrarily, when $\operatorname{Re}$ is higher than 2300, the fluids flow in a turbulent way [157]. A turbulent flow does not present any distinct streamlines. Due to the reduced size of the channels, viscous force is the main factor regulating the behaviours of the fluids in a microfluidics device [169].

A wide range of materials, including glass, polydimethylsiloxane (PDMS), hydrogel, polycarbonate, silicon and polytetrafluoroethylene, are routinely employed in the preparation of microfluidics devices [157, 170-172]. Every material displays own unique features. Generally, a glass capillary is coaxially assembled within a series of larger capillaries (round or square) [173175]. Amongst the advantages, glass capillary microfluidics devices are able to tolerate high pressure, high flow rate, as well as present good compatibility with organic solvents [157]. As for the disadvantages, the manual fabrication and assembling process leads to differences amongst each device [174]. PDMS can be moulded into a wide range of device geometries. On the negative side, the channel geometries of devices made from PDMS will change when encountering high pressure and high flow rate. Furthermore, they reveal incompatibility towards various common organic solvent [142, 157, 176].

When preparing drug nanocrystals, one of the most common geometries of the microfluidics devices is the Y-shaped one [166]. Usually, Y-shaped microfluidics devices possess one outlet and two inlets [166]. Zhao et al. prepared danazol nanocrystals employing Y-shaped microfluidics device (Figure 8a) [177]. During the production process, ethanol and water were employed as solvent and antisolvent, respectively with no surfactants added to the system. As the 
ratio of antisolvent and solvent increased, the drug nanoparticles showed smaller size and narrower size distribution (Figure 8b). The results of Fourier transform infrared spectroscopy (FTIR) and X-rays diffraction (XRD) confirmed the crystalline structure of the nanocrystals and demonstrated that there was no difference in the physical characteristics between the drug nanocrystal and raw danazol. Smaller particle size and larger surface area of the drug nanocrystal led to faster dissolution rate, where the drug nanocrystal and raw danazol after 5 min reached 100 and 35\%, respectively. Dong et al. synthesized fenofibrate nanoparticle by a sequential method combining first microfluidics, followed by spray drying [111]. The authors screened the characteristics of nanocrystals prepared from fenofibrate solutions in ethanol at different concentration, which contained $20 \%$ polyvinylpyrrolidone K30 (PVPK 30). The antisolvent (water) contained lactose (at a concentration of $12.67 \mathrm{mg} / \mathrm{mL}$ ). The solvent and antisolvent were pumped into the Y-shaped microfluidics device and the milky nanoparticle suspension was then delivered to a spray dryer through a silicon tube. The size of the drug nanoparticle varied from 196 to $296 \mathrm{~nm}$ by increasing the volume ratio of water and drug solution, flow rate, and drug concentration. Compared with the physical mixture, the drug nanoparticles showed higher drug dissolution rate of $97.09 \pm 3.04 \%$ after $30 \mathrm{~min}$, while the dissolution percentage of the physical mixture was only $36.24 \pm 2.61 \%$ after $2 \mathrm{~h}$. 
a

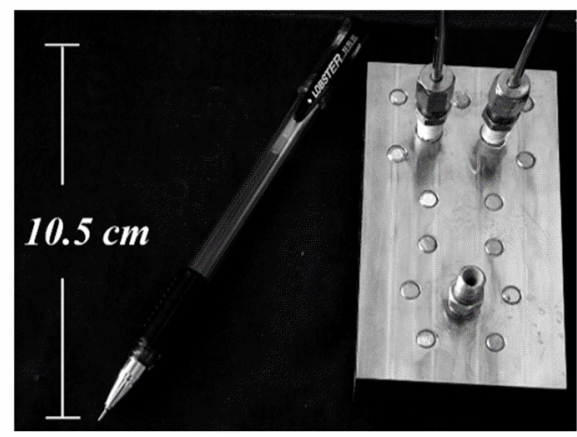

C

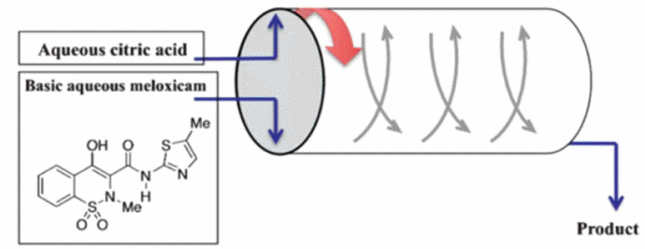

b
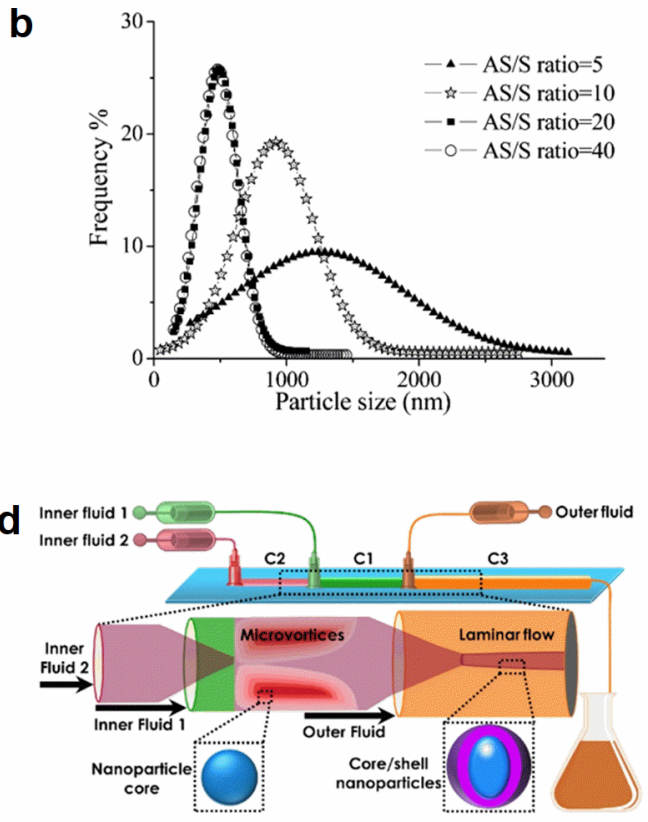

Figure 8. Drug nanocrystals prepared by microfluidics. (a) Photograph of Y-shaped microfluidics reactor. (b) Size distributions of danazol nanocrystals prepared at different antisolvent and solvent ratios. (c) Schematic illustration of the rotating tube processor. (d) Schematic illustration of the process of preparing drug nanocrystals through superfast sequential nanoprecipitation microfluidics. (a-b) Reproduced with permission from ref. [177], ( 2007, American Chemical Society; (c) Reproduced with permission from ref. [178], (C) 2013, Royal Society of Chemistry; (d) Reproduced with permission from ref. [146], ㅇ 2017, American Chemical Society.

Norfloxacin nanocrystals were prepared by microfluidics based impinging jet technology [179]. The jet velocities and energy dissipation in this kind of impinging jet reactor are several orders of magnitude higher than those achievable in the conventional one. In this system, dimethyl sulfoxide (DMSO) and water were used as the solvent and antisolvent, respectively. The increased pressure, decreased drug concentration, and supersaturation ratios resulted in a decrease in the size of nanocrystals. Moreover, the surfactant added in the system, Solutol, showed little influence on the size of drug nanocrystals. The solvent/antisolvent system had an impact on the crystalline structure of norfloxacin nanocrystal, however, in the DMSO/water 
system, the variation of shear rate of the process did not affect the drug crystalline structure. In addition, Tahara et al. prepared phenytoin, bezafibrate, flurbiprofen, and miconazole nanocrystals through microfluidics based on impinging jet technology [180]. In this microfluidics system, ethanol and a polyvinyl alcohol (PVA) solution (0.1\%) served as solvent and antisolvent, respectively. The size of drug nanocrystals prepared through microfluidics (431-525 nm) was smaller than that of drug nanocrystals produced by conventional bottom-up crystallization (637-1130 nm). Benefiting from their smaller particle size, the drug nanocrystal prepared by microfluidics had the highest dissolution rates compared to the physical mixtures of the commercial drugs and the drug nanocrystals prepared by conventional bottom-up crystallization, in which almost $100 \%$ of the drug was dissolved after $60 \mathrm{~min}$, with the exception of miconazole. In addition, phenytoin and flurbiprofen nanocrystals prepared by microfluidics showed ca. 3 times higher transport through the Caco-2 cell monolayer (a model established for evaluating in vitro the drug absorption in the intestine) and higher plasma concentrations after oral administration.

Dev et al. synthesized curcumin [181] and meloxicam [178, 182] nanocrystals by microfluidics rotating tube processor (Figure 8c). Curcumin nanocrystals with a diameter lower than $50 \mathrm{~nm}$ were prepared employing didodecyl-dimethylammonium bromide and pluronic F127 as stabilizer [181]. Comparing with the free drug, the curcumin nanoparticle displayed enhanced cytotoxicity when incubated with MCA-MB 468 and MCF-7 breast cancer cells. Meloxicam nanocrystals were synthesized by continuous microfluidics based on rotating tube processor (Figure 8c) [178, 182]. The particle size of the drug nanocrystal increased from $20 \mathrm{~nm}$ to $200 \mathrm{~nm}$ when the rotational speed varied from 500 to $1500 \mathrm{rpm}$ [182]. Meloxicam was encapsulated with poloxamer 188 or polyelectrolytes to ensure the stability of the drug nanocrystals [178, 182]. The bare and encapsulated meloxicam nanocrystals displayed enhanced dissolution rate in comparison with the micronized drug particles [182]. Meloxicam nanoparticles coated by 
polyelectrolytes in a range of concentrations from 10 to $500 \mu \mathrm{M}$ showed no toxicity to pheochromocytoma and mouse fibroblast 3T3 cells [178].

Sorafenib (SFN) and itraconazole (ICZ) nanocrystals encapsulated by folic acid (FA) conjugated spermine-functionalized acetalated dextran (ADS), HSFN@ADS-FA and ICZ@ADS-FA, were produced through multistep microfluidics nanoprecipitation [183]. The HSFN@ADS-FA revealed core-shell structure, ultrahigh drug loading degree $(\sim 58.4 \%)$ and a $\mathrm{pH}$ sensitive release profile. Approximately 9.3\% of SFN was released from the HSFN@ADS-FA at pH 7.4, while all SFN could be released from the nanovector at $\mathrm{pH} 5.0$ within $2 \mathrm{~h}$. Owning to the ultrahigh drug loading degree, HSFN@ADS-FA showed about 54-times lower half-maximal inhibitory concentration than that of a nanovector prepared by conventional single microfluidics nanoprecipitation. In addition, another core-shell nanocomposites with paclitaxel (PTX) and SFN nanocrystal core and hypromellose acetate succinate (HF) shell (PTX@HF and SFN@HF) was developed through superfast sequential nanoprecipitation microfluidics (Figure 8d) [146]. The inner fluid 1, inner fluid 2, and outer fluid refer to core and shell precursors, nonsolvent for the core precursor only and nonsolvent for both core and shell precursors, respectively. After the formation of the drug nanocrystal during the first mixing, the second mixing lead to the precipitation of HF on the surface of drug nanocrystal and the formation of core shell structure. Although no stabilizers were added, PTX@HF and SFN@HF showed higher stability than the freshly prepared bare PTX and SFN particles, because of the short time interval between the sequential precipitation processes and the formation of polymeric shell on the surface of drug nanocrystals. The PTX@HF and SFN@HF nanocrystals showed ultrahigh drug loading degree (42.6 and 45.2\%, respectively), $\mathrm{pH}$ sensitive drug release, an increased drug dissolution kinetics, and high-throughput production rate at $\sim 700 \mathrm{~g} /$ day on a single device.

\subsubsection{Supercritical fluid technology}


Supercritical fluid (SCF) technology has been employed to modify the solid state characteristics of the active principle ingredient powder, particularly for poorly water-soluble drug compounds [184]. Amongst the properties modified after supercritical precipitation are size, crystallinity, polymorphism, shape, and surface [185]. Moreover, the use of SCF has been evaluated also in the micronization of biopharmaceuticals and in the formulation of co-crystals [186, 187]. Supercritical carbon dioxide $\left(\mathrm{sCO}_{2}\right)$ is widely employed as SCF for the precipitation of micro- and nanoparticles, including drug nanocrystals and amorphous drug nanoparticles, due to its favorable properties (mild critical conditions, $\mathrm{T}=31.1{ }^{\circ} \mathrm{C}, \mathrm{p}=7.38 \mathrm{MPa}$, low cost, high safety, nonflammability, easiness in the removal of the antisolvent by reducing the pressure) $[185,186,188]$.

In rapid expansion of supercritical fluid (RESS), the SCF is used as solvent for the drug and the precipitation of the nanocrystals occurs after an expansion of the gas in the collection chamber due to the induction of a drug supersaturation status in the supercritical fluid [189]. This process is suitable only for drugs that are soluble in the SCF, where the solution is prepared into an extractor, a pressurized container, before being sprayed into the collection vessel [190]. The parameters influencing the process and, thereby, the size and the yield of the nanocrystals recovered are the pressure and temperature, flow rate of the SCF, geometry and diameter of the spraying nozzle [190].

Supercritical antisolvent (SAS) precipitation technique involves the use of the SCF as an antisolvent, to induce precipitation of the nanocrystals, from a solution of the drug in organic solvent, by a fast increase in the SCF molar fraction during the flight of the atomized drops in the SCF continuum $[190,191]$. Furthermore, this can be considered a continuous process, leading to more reproducible results because the formation of the crystals occurs in a steady state when compared to RESS [190]. SAS process is routinely employed for the precipitation of amorphous 
drug nanoparticles rather than drug nanocrystals, as in the case of atorvastatin or tacrolimus [185, 192].

One variant of the SAS process is the Supercritical Enhanced Dispersion Solution (SEDS): the reactor presents multichannel nozzles while the phases are mixed in a pre-chamber [190].

The SCF can be further employed as dispersing agent in the particles from PGSS technique: SCF (in a lower amount compared to both RESS and SAS) is mixed with the drug of interest in a prechamber to a homogenous molten fluid. This fluid is then moved to another chamber, at lower pressure, where expansion of the SCF occurs, leading to the precipitation of the crystals [190]. The main advantage of this techniques relies on its being solvent free, thereby optimal for the precipitation of biopharmaceuticals, e.g., for the encapsulation of proteins within polymeric microstructures [193, 194].

The main studies focusing on the production of drug nanocrystals and nano co-crystals by supercritical fluid technology are summarized in Table 7. A more complete discussion about the technique can be found in the article "Supercritical carbon dioxide-based technologies for the production of drug nanoparticles/nanocrystals - a comprehensive review" by Padrela et al., in this issue. 


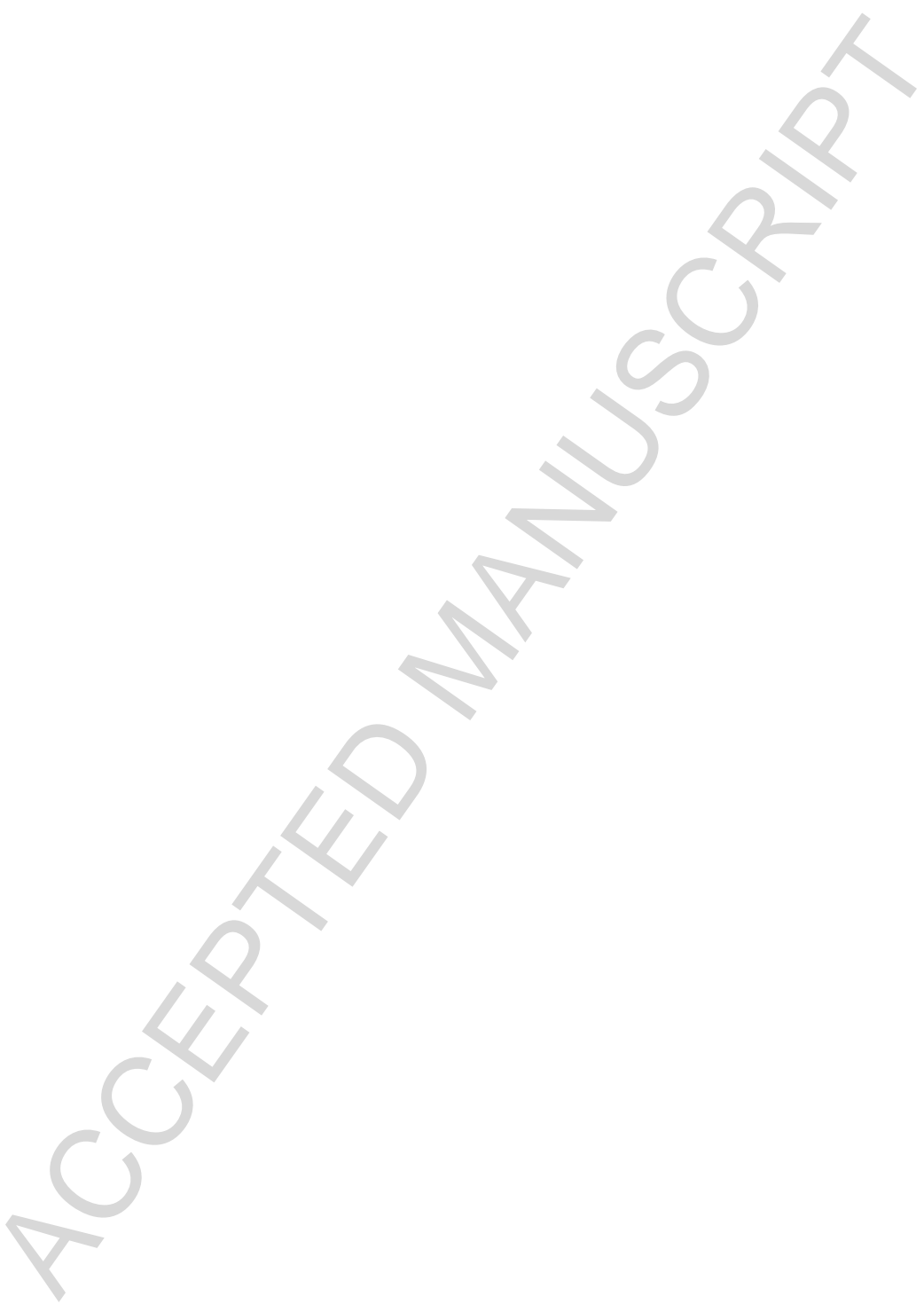


Table 7. Drug Nanocrystals prepared by supercritical fluid processes.

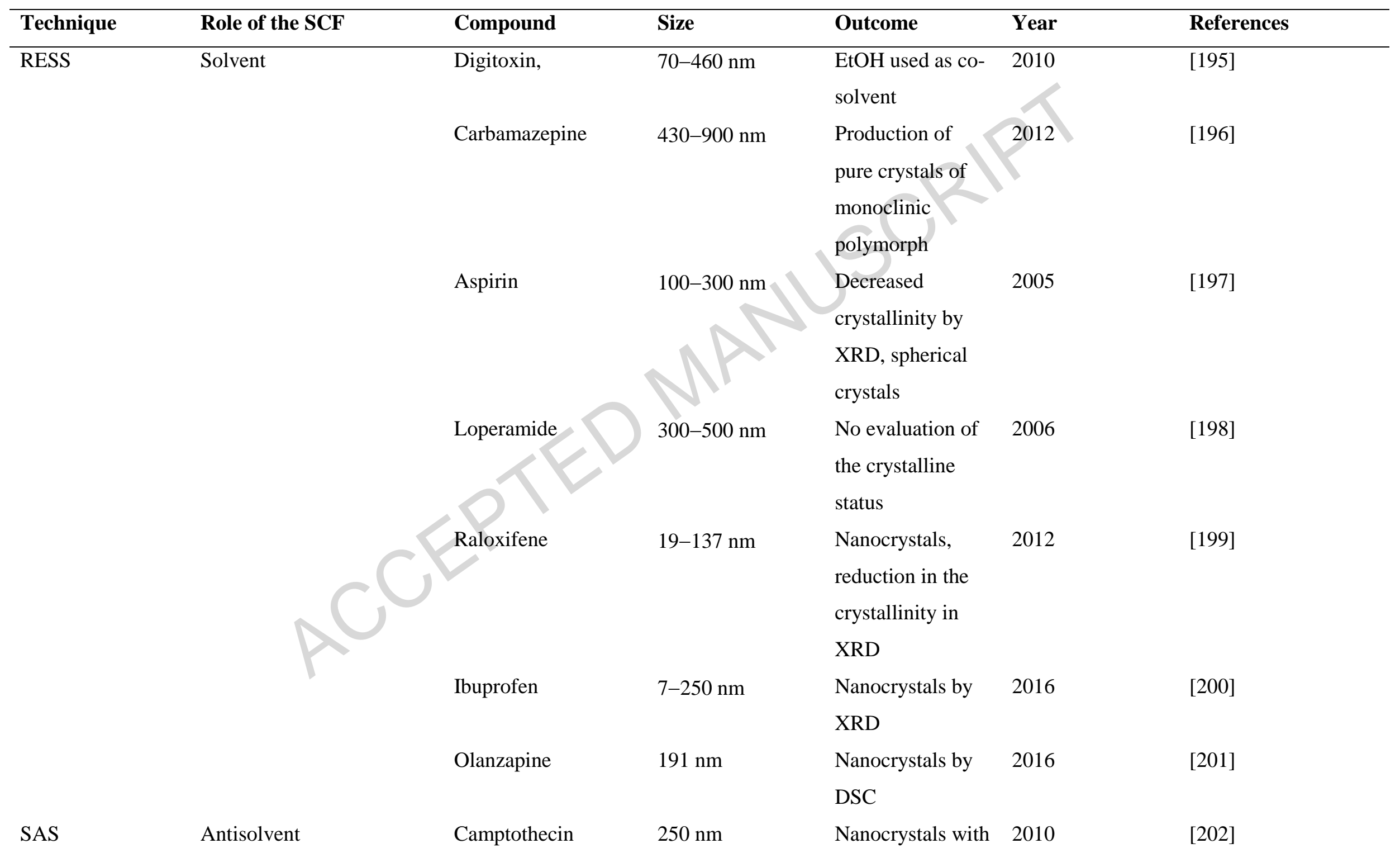




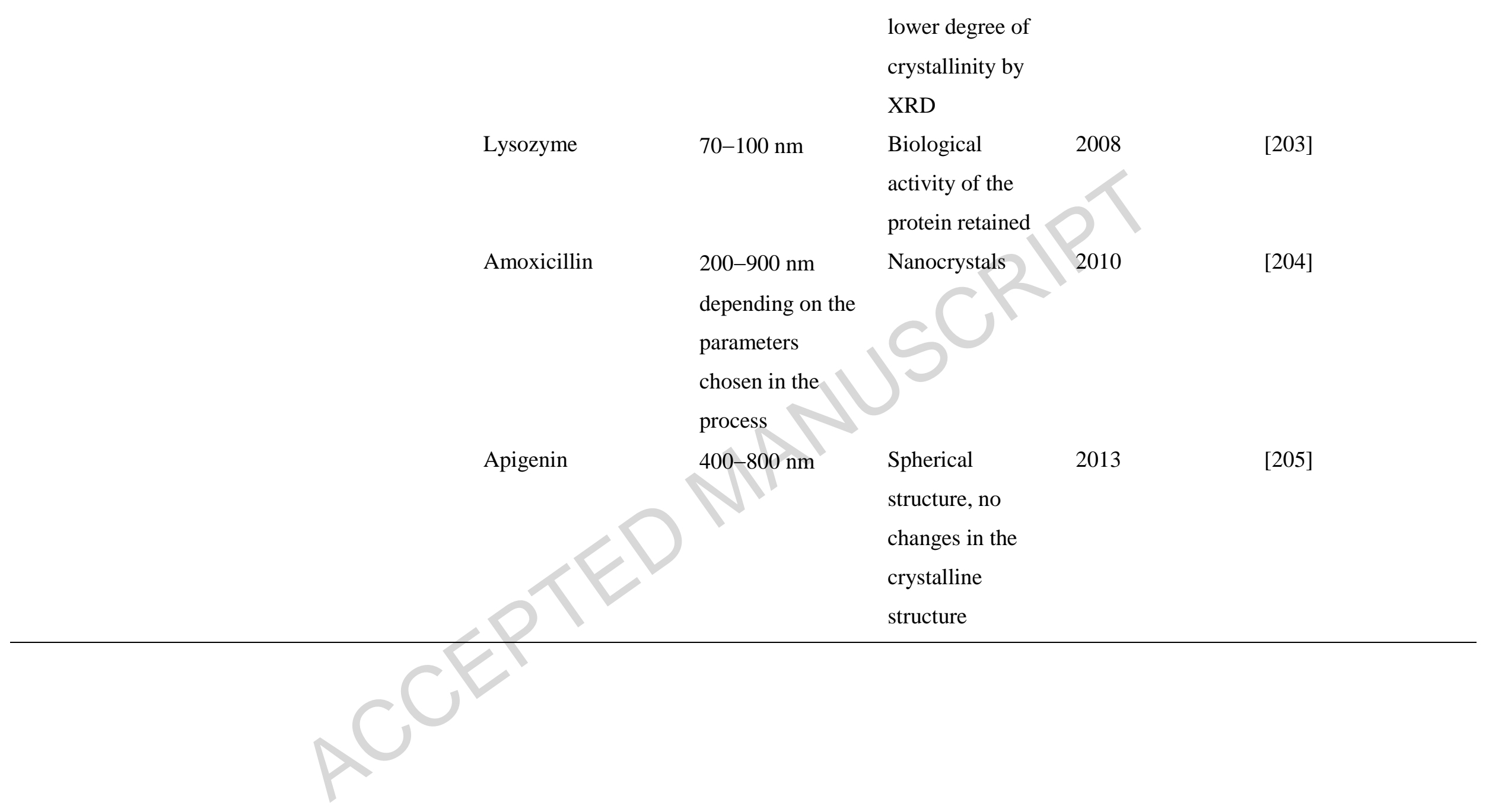




\subsubsection{Solvent evaporation and spray drying}

Spray drying is widely employed in the production of nanocrystals [206]. The process involves the atomization of a fluid (containing the drug in solution) by an atomizer into a hot drying gas (commonly, air) [207].

The effects of the variables (flow rate, diameter of the atomizer, fluid properties, and equipment design) on the size and shape of the particles obtained after spray drying have been reviewed in detail by Nandiyanto et al [208]. Moreover, NanoCrySP ${ }^{\circledR}$ represent a recent technology developed for the industrial production of nanocrystals in a spray dryer: the solution of the drug is spray together with small molecules that facilitate the beginning of the nucleation process, leading to the formation of drug nanocrystals into a solid dispersion of small molecules [209]. A downside of this technique is the high fraction of aggregates retrieved after the process which requires the addition of stabilizers.

However, the production of nanoparticles in a spray dryer is limited, amongst others factors, by the difficulties in the collection of fine particles by the cyclone [210]. The Nano Spray Dryer B-90 was developed to enable high yield production of nanosized particles by spray drying [211]. We refer the reader to the article in this issue by Sverdlov and Sosnik "Electrohydrodynamic atomization and spray-drying for the production of pure drug nanocrystals and co-crystals", for a deep insight into the preparation of nanocrystals by spray-drying.

Freeze drying represent another solvent-evaporation procedure that leads to the production of nanocrystals. In order to obtain nanocrystals from this process, the organic solution of the drug is mixed with the antisolvent, which contains a cryoprotectant [212]. The solutions are immediately frozen and then dried. The crystallization process can occur either during the freezing process or during the drying one: the parameters to optimize in order to obtain smaller crystals are the concentration of the cryoprotectant (higher for crystallization occurring during the freezing phase, 
lower in the other option), and the freezing speed. Spray freezing into liquid allows the production of nanosized amorphous drug particles by spraying a solution of the drug dissolved in an organic solvent, in liquid nitrogen [109]. The parameters influencing the size are the type of solvent chosen (either water or organic, or a mix of the two) and the concentration of the drug in solution in the precipitation of carbamazepine [213].

\subsection{Combination of bottom-up and top-down approaches}

Combination processes involve the use of both bottom-up and top-down processes in sequence, as depicted in Figure 9. Usually, nanocrystals are first precipitated by bottom up methods, and then, are passed through one of the top-down process (HPH, ultrasounds, or high energy mixing) [109]. The advantages of the combination of process center around the production of smaller nanocrystals, however, the combination is used only when extremely needed, given the increase in the costs due to the double of preparation procedure [17]. 


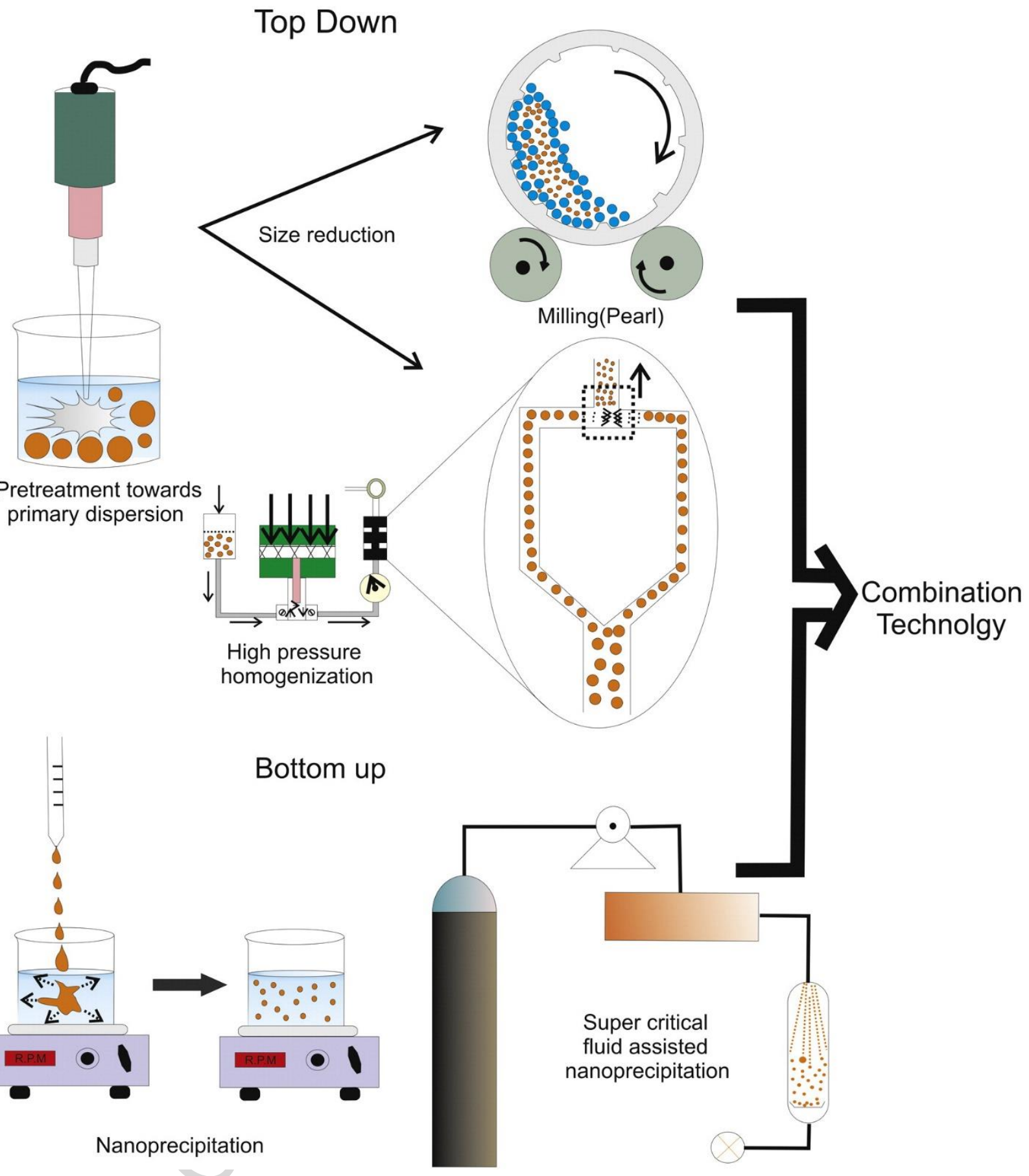

Figure 9. Schematic illustrating the combination between bottom-up and top-down processes. Reproduced with permission from ref. [214], (C) 2014, Elsevier B.V.

The first technique developed and patented was Nanoedge ${ }^{\circledR}$, which couples a solvent/antisolvent precipitation step with an annealing step given by HPH [215]. Other combination processes are those included in the Smart Crystals ${ }^{\circledR}$ technology, where the pre-treatment processes include all the 
techniques mentioned above for the bottom-up production of nanocrystals, followed by HPH [216]. In detail, Nano Pure ${ }^{\circledR}$ involves no pre-treatment, H42 uses spray drying for the production of the crystals, H69 antisolvent precipitation, H96 lyophilization, while CT processes the drug by media milling [61].

\section{Challenges for scale-up production}

The main challenges with the industrial production of nanocrystals are related with the scaling-up and the possibility for continuous manufacturing. As for bottom-up technologies, the use of SCF, particularly SAS configuration, enables a ready scale-up, with the possibility to implement also a continuous manufacturing process [217]. Other techniques are instead more indicated for a batch production (conventional precipitation, sonoprecipitation). Microfluidics represents another versatile technique to continuously manufacturing nanocrystals, with high yields [146].

Electrospray represents one of the solutions enabling continuous manufacturing of drug nanocrystals, for example, nanometer-sized crystals of niflumic acid were produced from an ultrafine mist, leading to particle size between 200 and 800 nm, as shown in Figure 10A and 10B. However, the presence of stabilizers was needed for obtaining a difference in the dissolution profile compared with the bulk drug [218]. Nanocrystals of carbamazepine (Figure 10C) were obtained by electrospray and the authors correlated the variables (drug concentration, conductivity, flow rate, voltage, and current) to the crystal sizes that fell within the range $320-1756 \mathrm{~nm}$, depending on the experimental setup [219]. 


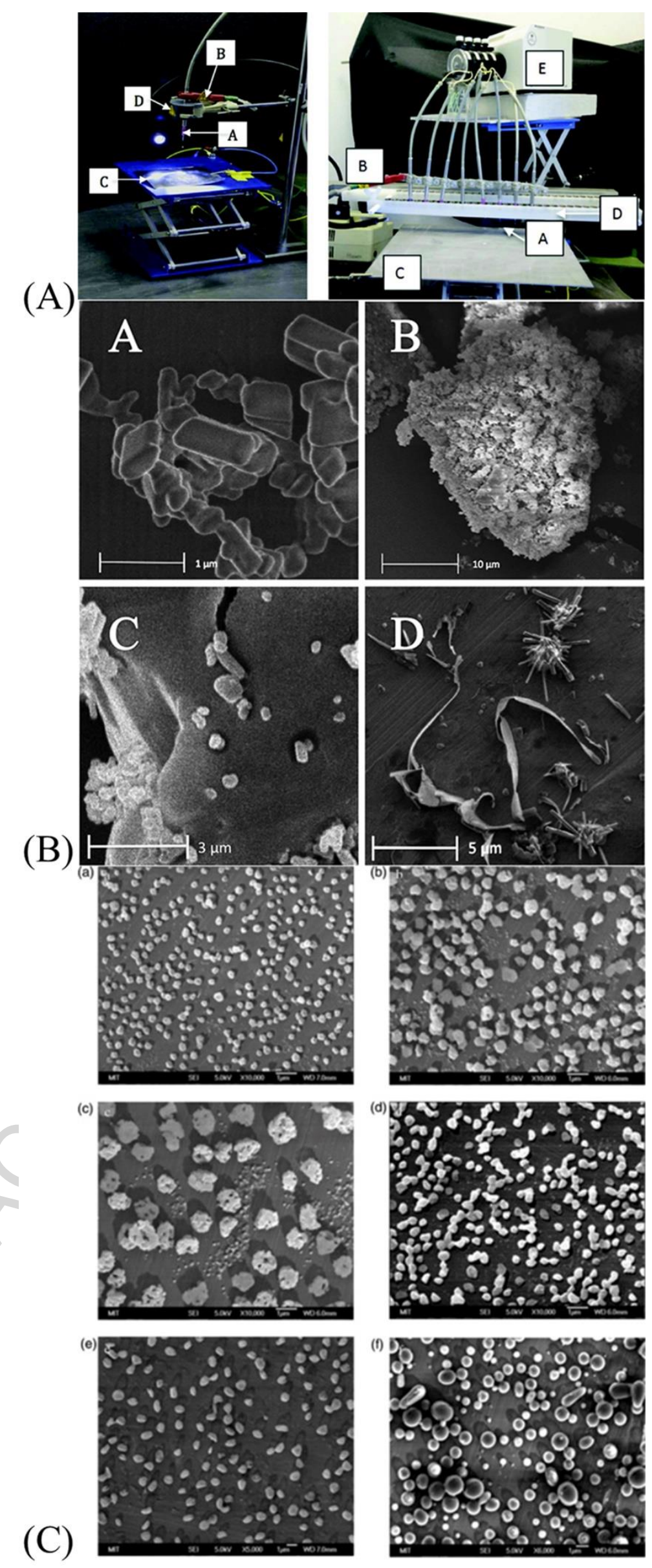


Figure 10. (A) Electrospray setups: on the left single sprayer and on the right 8-channel sprayer. (B) SEM images of the nanocrystals of niflumic acid obtained with the electrospray technique. (C) SEM micrographs of carbamazepine nanocrystals produced by electrospraying. (A) and (B) reproduced with permission from ref. [218], (c) 2012 American Chemical Society. (C) Reproduced with permission from ref. [219], (c) 2011, Elsevier B.V. and the American Pharmacists Association.

Electrospray is also employed in the production of co-crystals, as reported by Patil et al. However no specification on the size of the crystal is provided [220,221].

Overall, several techniques allow an easy scale-up or can be integrated within a continuous manufacturing plant.

\section{Conclusion and future prospective}

The relevance of nanocrystals in drug development is well-established. Several techniques are routinely used at the industrial level, with a wide range of formulations already on the market or under clinical trials. The traditional top-down processes offer reliable solutions for easy scaling-up, but present also disadvantages related to possible contaminations from the milling mediums, drug degradation, and longer time of processing. On the contrary, bottom-up processes offer an easy, greener alternative to the energy-dispersive top-down techniques. However, the control over the size and the stabilization of the product are still less reproducible than for the top-down processes. SCF constitute an excellent solution to prepare nanocrystals with optimal properties, with the possibility of connecting them to a continuous manufacturing line. Finally, microfluidics is bringing along advantages given by the high degree of control achievable in the system, the need for limited volume of solvents, and the high production yield (in some cases up to $700 \mathrm{~g} / \mathrm{day}$ from a single device), together with an easy scaling-up (by having multiple chips either in series or in parallel). 
Overall, we are thereby witnessing three different generations of processes for the production of nanocrystals, from the well-established top-down approach, to the first industrial applications of some bottom-up techniques, to the first steps of the confinement methods (microfluidcs) in research.

\section{Acknowledgments}

P. Figueiredo acknowledges the Finnish Cultural Foundation for a research grant (decision no. 00170202). P. Zhang acknowledges the Doctoral Programme in Drug Research, Faculty of Pharmacy, University of Helsinki. Prof. H. A. Santos acknowledges financial support from the University of Helsinki Research Funds, the HiLIFE Research Funds, the Sigrid Juselius Foundation (Grant 4704580), and the European 584 Research Council under the European Union's Seventh Framework Programme (FP/2007-2013; Grant 310892).

\section{References}

[1] R.H. Müller, C.M. Keck, Twenty years of drug nanocrystals: Where are we, and where do we go?, European Journal of Pharmaceutics and Biopharmaceutics, 80 (2012) 1-3.

[2] L. Gao, D. Zhang, M. Chen, Drug nanocrystals for the formulation of poorly soluble drugs and its application as a potential drug delivery system, Journal of Nanoparticle Research, 10 (2008) 845862.

[3] A. Hafner, J. Lovric, G.P. Lakos, I. Pepic, Nanotherapeutics in the EU: an overview on current state and future directions, Int J Nanomedicine, 9 (2014) 1005-1023.

[4] M. Malamatari, K.M.G. Taylor, S. Malamataris, D. Douroumis, K. Kachrimanis, Pharmaceutical nanocrystals: production by wet milling and applications, Drug Discovery Today, (2018).

[5] H.A. Santos, L. Peltonen, T. Limnell, J. Hirvonen, Mesoporous materials and nanocrystals for enhancing the dissolution behavior of poorly water-soluble drugs, Curr Pharm Biotechnol, 14 (2013) 926-938.

[6] J.-U.A.H. Junghanns, R.H. Müller, Nanocrystal technology, drug delivery and clinical applications, International Journal of Nanomedicine, 3 (2008) 295-310.

[7] A.T.M. Serajuddin, Salt formation to improve drug solubility, Advanced Drug Delivery Reviews, 59 (2007) 603-616.

[8] T. Loftsson, M.E. Brewster, Pharmaceutical applications of cyclodextrins. 1. Drug solubilization and stabilization, Journal of Pharmaceutical Sciences, 85 (1996) 1017-1025.

[9] A. Vyas, S. Saraf, S. Saraf, Cyclodextrin based novel drug delivery systems, Journal of Inclusion Phenomena and Macrocyclic Chemistry, 62 (2008) 23-42. 
[10] S. Choudhary, L. Gupta, S. Rani, K. Dave, U. Gupta, Impact of Dendrimers on Solubility of Hydrophobic Drug Molecules, Frontiers in Pharmacology, 8 (2017) 261.

[11] T.D. Thi, M. Van Speybroeck, V. Barillaro, J. Martens, P. Annaert, P. Augustijns, J. Van Humbeeck, J. Vermant, G. Van den Mooter, Formulate-ability of ten compounds with different physicochemical profiles in SMEDDS, European Journal of Pharmaceutical Sciences, 38 (2009) 479-488.

[12] F. Shakeel, M.S. Faisal, Nanoemulsion: A promising tool for solubility and dissolution enhancement of celecoxib, Pharmaceutical Development and Technology, 15 (2010) 53-56.

[13] C.J.H. Porter, N.L. Trevaskis, W.N. Charman, Lipids and lipid-based formulations: optimizing the oral delivery of lipophilic drugs, Nature Reviews Drug Discovery, 6 (2007) 231.

[14] C.M. Keck, R.H. Müller, Drug nanocrystals of poorly soluble drugs produced by high pressure homogenisation, European Journal of Pharmaceutics and Biopharmaceutics, 62 (2006) 3-16.

[15] R.H. Müller, S. Gohla, C.M. Keck, State of the art of nanocrystals - Special features, production, nanotoxicology aspects and intracellular delivery, European Journal of Pharmaceutics and Biopharmaceutics, 78 (2011) 1-9.

[16] V.B. Junyaprasert, B. Morakul, Nanocrystals for enhancement of oral bioavailability of poorly water-soluble drugs, Asian Journal of Pharmaceutical Sciences, 10 (2015) 13-23.

[17] L. Peltonen, J. Hirvonen, Drug nanocrystals - Versatile option for formulation of poorly soluble materials, International Journal of Pharmaceutics, 537 (2018) 73-83.

[18] U. Wais, A.W. Jackson, T. He, H. Zhang, Nanoformulation and encapsulation approaches for poorly water-soluble drug nanoparticles, Nanoscale, 8 (2016) 1746-1769.

[19] R.C. Nagarwal, R. Kumar, M. Dhanawat, N. Das, J.K. Pandit, Nanocrystal technology in the delivery of poorly soluble drugs: an overview, Current drug delivery, 8 (2011) 398-406.

[20] F. Kesisoglou, S. Panmai, Y. Wu, Nanosizing - Oral formulation development and biopharmaceutical evaluation, Advanced Drug Delivery Reviews, 59 (2007) 631-644.

[21] A.A. Noyes, W.R. Whitney, THE RATE OF SOLUTION OF SOLID SUBSTANCES IN THEIR OWN SOLUTIONS, Journal of the American Chemical Society, 19 (1897) 930-934.

[22] A.T. Florence, D. Attwood, Physicochemical principles of pharmacy, Pharmaceutical press2011.

[23] G. Buckton, A.E. Beezer, The relationship between particle size and solubility, International Journal of Pharmaceutics, 82 (1992) R7-R10.

[24] J. Moschwitzer, R. Muller, Drug Nanocrystals-The Universal Formulation Approach for Poorly Soluble Drugs, DRUGS AND THE PHARMACEUTICAL SCIENCES, 166 (2007) 71.

[25] B. Van Eerdenbrugh, G. Van den Mooter, P. Augustijns, Top-down production of drug nanocrystals: Nanosuspension stabilization, miniaturization and transformation into solid products, International Journal of Pharmaceutics, 364 (2008) 64-75.

[26] Y. Yi, L. Tu, K. Hu, W. Wu, J. Feng, The construction of puerarin nanocrystals and its pharmacokinetic and in vivo-in vitro correlation (IVIVC) studies on beagle dog, Colloids Surf B Biointerfaces, 133 (2015) 164-170.

[27] S.K. Singh, K.K. Srinivasan, K. Gowthamarajan, D.S. Singare, D. Prakash, N.B. Gaikwad, Investigation of preparation parameters of nanosuspension by top-down media milling to improve the dissolution of poorly water-soluble glyburide, European Journal of Pharmaceutics and Biopharmaceutics, 78 (2011) 441-446.

[28] V. Dhapte, V. Pokharkar, Polyelectrolyte Stabilized Antimalarial Nanosuspension Using Factorial Design Approach, Journal of Biomedical Nanotechnology, 7 (2011) 139-141.

[29] P. Quan, K. Shi, H. Piao, H. Piao, N. Liang, D. Xia, F. Cui, A novel surface modified nitrendipine nanocrystals with enhancement of bioavailability and stability, International Journal of Pharmaceutics, 430 (2012) 366-371.

[30] Y. Wang, Y. Zheng, L. Zhang, Q. Wang, D. Zhang, Stability of nanosuspensions in drug delivery, Journal of Controlled Release, 172 (2013) 1126-1141. 
[31] H. Rachmawati, L.A. Shaal, R.H. Müller, C.M. Keck, Development of Curcumin Nanocrystal: Physical Aspects, Journal of Pharmaceutical Sciences, 102 (2013) 204-214.

[32] I. Ghosh, S. Bose, R. Vippagunta, F. Harmon, Nanosuspension for improving the bioavailability of a poorly soluble drug and screening of stabilizing agents to inhibit crystal growth, International Journal of Pharmaceutics, 409 (2011) 260-268.

[33] A. Tuomela, J. Hirvonen, L. Peltonen, Stabilizing Agents for Drug Nanocrystals: Effect on Bioavailability, Pharmaceutics, 8 (2016) 16.

[34] J. Lee, S.-J. Lee, J.-Y. Choi, J.Y. Yoo, C.-H. Ahn, Amphiphilic amino acid copolymers as stabilizers for the preparation of nanocrystal dispersion, European Journal of Pharmaceutical Sciences, 24 (2005) 441-449.

[35] K.A. Mahmoud, J.A. Mena, K.B. Male, S. Hrapovic, A. Kamen, J.H.T. Luong, Effect of Surface Charge on the Cellular Uptake and Cytotoxicity of Fluorescent Labeled Cellulose Nanocrystals, ACS Applied Materials \& Interfaces, 2 (2010) 2924-2932.

[36] B. Sun, Y. Yeo, Nanocrystals for the parenteral delivery of poorly water-soluble drugs, Current opinion in solid state \& materials science, 16 (2012) 295-301.

[37] W. Sun, W. Tian, Y. Zhang, J. He, S. Mao, L. Fang, Effect of novel stabilizers--cationic polymers on the particle size and physical stability of poorly soluble drug nanocrystals, Nanomedicine : nanotechnology, biology, and medicine, 8 (2012) 460-467.

[38] S. Verma, S. Kumar, R. Gokhale, D.J. Burgess, Physical stability of nanosuspensions: Investigation of the role of stabilizers on Ostwald ripening, International Journal of Pharmaceutics, 406 (2011) 145-152.

[39] D. Douroumis, S.A. Ross, A. Nokhodchi, Advanced methodologies for cocrystal synthesis, Advanced Drug Delivery Reviews, 117 (2017) 178-195.

[40] D.J. Berry, J.W. Steed, Pharmaceutical cocrystals, salts and multicomponent systems; intermolecular interactions and property based design, Advanced Drug Delivery Reviews, 117 (2017) 3-24.

[41] D.D. Gadade, S.S. Pekamwar, Pharmaceutical Cocrystals: Regulatory and Strategic Aspects, Design and Development, Advanced Pharmaceutical Bulletin, 6 (2016) 479-494.

[42] P. Vishweshwar, J.A. McMahon, J.A. Bis, M.J. Zaworotko, Pharmaceutical co-crystals, Journal of Pharmaceutical Sciences, 95 (2006) 499-516.

[43] A.V. Yadav, A.S. Shete, A.P. Dabke, P.V. Kulkarni, S.S. Sakhare, Co-Crystals: A Novel Approach to Modify Physicochemical Properties of Active Pharmaceutical Ingredients, Indian Journal of Pharmaceutical Sciences, 71 (2009) 359-370.

[44] C.B. Aakeröy, S. Forbes, J. Desper, Using Cocrystals To Systematically Modulate Aqueous Solubility and Melting Behavior of an Anticancer Drug, Journal of the American Chemical Society, 131 (2009) 17048-17049.

[45] C.B. Aakeröy, A.M. Beatty, B.A. Helfrich, A High-Yielding Supramolecular Reaction, Journal of the American Chemical Society, 124 (2002) 14425-14432.

[46] C.B. Aakeroy, D.J. Salmon, Building co-crystals with molecular sense and supramolecular sensibility, CrystEngComm, 7 (2005) 439-448.

[47] O. Almarsson, M.J. Zaworotko, Crystal engineering of the composition of pharmaceutical phases. Do pharmaceutical co-crystals represent a new path to improved medicines?, Chemical Communications, (2004) 1889-1896.

[48] P. Khadka, J. Ro, H. Kim, I. Kim, J.T. Kim, H. Kim, J.M. Cho, G. Yun, J. Lee, Pharmaceutical particle technologies: An approach to improve drug solubility, dissolution and bioavailability, asian journal of pharmaceutical sciences, 9 (2014) 304-316.

[49] E. Merisko-Liversidge, G.G. Liversidge, E.R. Cooper, Nanosizing: a formulation approach for poorly-water-soluble compounds, European Journal of Pharmaceutical Sciences, 18 (2003) 113120. 
[50] W.W. Chin, J. Parmentier, M. Widzinski, E.H. Tan, R. Gokhale, A brief literature and patent review of nanosuspensions to a final drug product, J Pharm Sci, 103 (2014) 2980-2999.

[51] M. Li, M. Azad, R. Davé, E. Bilgili, Nanomilling of Drugs for Bioavailability Enhancement: A Holistic Formulation-Process Perspective, Pharmaceutics, 8 (2016) 17.

[52] J. Salazar, R.H. Müller, J.P. Möschwitzer, Performance Comparison of two Novel Combinative Particle-Size-Reduction Technologies, Journal of Pharmaceutical Sciences, 102 (2013) 1636-1649.

[53] J. Salazar, R.H. Müller, J.P. Möschwitzer, Combinative Particle Size Reduction Technologies for the Production of Drug Nanocrystals, Journal of Pharmaceutics, 2014 (2014) 14.

[54] Y. Lu, Y. Li, W. Wu, Injected nanocrystals for targeted drug delivery, Acta Pharmaceutica Sinica. B, 6 (2016) 106-113.

[55] R.H. Müller, C. Jacobs, O. Kayser, Nanosuspensions as particulate drug formulations in therapy: Rationale for development and what we can expect for the future, Advanced Drug Delivery Reviews, 47 (2001) 3-19.

[56] S. Verma, R. Gokhale, D.J. Burgess, A comparative study of top-down and bottom-up approaches for the preparation of micro/nanosuspensions, International Journal of Pharmaceutics, 380 (2009) 216-222.

[57] L. Peltonen, J. Hirvonen, Pharmaceutical nanocrystals by nanomilling: critical process parameters, particle fracturing and stabilization methods, Journal of Pharmacy and Pharmacology, 62 (2010) 1569-1579.

[58] G.E. Parsons, G. Buckton, S.M. Chatham, The use of surface energy and polarity determinations to predict physical stability of non-polar, non-aqueous suspensions, International Journal of Pharmaceutics, 83 (1992) 163-170.

[59] R.O. Williams, 3rd, J. Brown, J. Liu, Influence of micronization method on the performance of a suspension triamcinolone acetonide pressurized metered-dose inhaler formulation, Pharm Dev Technol, 4 (1999) 167-179.

[60] J.Y. Heng, F. Thielmann, D.R. Williams, The effects of milling on the surface properties of form I paracetamol crystals, Pharm Res, 23 (2006) 1918-1927.

[61] R. Shegokar, R.H. Müller, Nanocrystals: Industrially feasible multifunctional formulation technology for poorly soluble actives, International Journal of Pharmaceutics, 399 (2010) 129-139.

[62] L. Gao, G. Liu, J. Ma, X. Wang, L. Zhou, X. Li, F. Wang, Application of drug nanocrystal technologies on oral drug delivery of poorly soluble drugs, Pharm Res, 30 (2013) 307-324.

[63] G.G. Liversidge, K.C. Cundy, J.F. Bishop, D.A. Czekai, Surface modified drug nanoparticles, Google Patents, 1992.

[64] E.M. Merisko-Liversidge, G.G. Liversidge, Drug Nanoparticles: Formulating Poorly WaterSoluble Compounds, Toxicologic Pathology, 36 (2008) 43-48.

[65] E. Merisko-Liversidge, G.G. Liversidge, Nanosizing for oral and parenteral drug delivery: a perspective on formulating poorly-water soluble compounds using wet media milling technology, Adv Drug Deliv Rev, 63 (2011) 427-440.

[66] B. Van Eerdenbrugh, J. Vermant, J.A. Martens, L. Froyen, J. Van Humbeeck, P. Augustijns, G. Van den Mooter, A screening study of surface stabilization during the production of drug nanocrystals, Journal of Pharmaceutical Sciences, 98 (2009) 2091-2103.

[67] T. Niwa, S. Miura, K. Danjo, Universal wet-milling technique to prepare oral nanosuspension focused on discovery and preclinical animal studies - Development of particle design method, International Journal of Pharmaceutics, 405 (2011) 218-227.

[68] J. Lee, J.Y. Choi, C.H. Park, Characteristics of polymers enabling nano-comminution of waterinsoluble drugs, International Journal of Pharmaceutics, 355 (2008) 328-336.

[69] J.-Y. Choi, J.Y. Yoo, H.-S. Kwak, B. Uk Nam, J. Lee, Role of polymeric stabilizers for drug nanocrystal dispersions, Current Applied Physics, 5 (2005) 472-474. 
[70] Z. Deng, S. Xu, S. Li, Understanding a relaxation behavior in a nanoparticle suspension for drug delivery applications, International Journal of Pharmaceutics, 351 (2008) 236-243.

[71] B. Van Eerdenbrugh, L. Froyen, J.A. Martens, N. Blaton, P. Augustijns, M. Brewster, G. Van den Mooter, Characterization of physico-chemical properties and pharmaceutical performance of sucrose co-freeze-dried solid nanoparticulate powders of the anti-HIV agent loviride prepared by media milling, International Journal of Pharmaceutics, 338 (2007) 198-206.

[72] A. Monteiro, A. Afolabi, E. Bilgili, Continuous production of drug nanoparticle suspensions via wet stirred media milling: a fresh look at the Rehbinder effect, Drug Development and Industrial Pharmacy, 39 (2013) 266-283.

[73] R.H. Müller, A. Akkar, Drug nanocrystals of poorly soluble drugs, Encyclopedia of Nanoscience and Nanotechnology, (2004) 627-638.

[74] P. Sharma, W.A. Denny, S. Garg, Effect of wet milling process on the solid state of indomethacin and simvastatin, International Journal of Pharmaceutics, 380 (2009) 40-48.

[75] S.P. Chamarthy, R. Pinal, The nature of crystal disorder in milled pharmaceutical materials, Colloids and Surfaces A: Physicochemical and Engineering Aspects, 331 (2008) 68-75.

[76] K.J. Crowley, G. Zografi, Cryogenic grinding of indomethacin polymorphs and solvates: Assessment of amorphous phase formation and amorphous phase physical stability, Journal of Pharmaceutical Sciences, 91 (2002) 492-507.

[77] M. Malamatari, S. Somavarapu, K.M.G. Taylor, G. Buckton, Solidification of nanosuspensions for the production of solid oral dosage forms and inhalable dry powders, Expert Opinion on Drug Delivery, 13 (2016) 435-450.

[78] M.V. Chaubal, C. Popescu, Conversion of Nanosuspensions into Dry Powders by Spray Drying: A Case Study, Pharm Res-Dordr, 25 (2008) 2302-2308.

[79] E. Merisko-Liversidge, Nanosizing: "End-to-End" Formulation Strategy for Poorly WaterSoluble Molecules, in: A.C. Templeton, S.R. Byrn, R.J. Haskell, T.E. Prisinzano (Eds.) Discovering and Developing Molecules with Optimal Drug-Like Properties, Springer New York, New York, NY, 2015, pp. 437-467.

[80] Y. Wu, A. Loper, E. Landis, L. Hettrick, L. Novak, K. Lynn, C. Chen, K. Thompson, R. Higgins, U. Batra, S. Shelukar, G. Kwei, D. Storey, The role of biopharmaceutics in the development of a clinical nanoparticle formulation of MK-0869: a Beagle dog model predicts improved bioavailability and diminished food effect on absorption in human, International Journal of Pharmaceutics, 285 (2004) 135-146.

[81] J.P. Möschwitzer, Drug nanocrystals in the commercial pharmaceutical development process, International Journal of Pharmaceutics, 453 (2013) 142-156.

[82] J. Beirowski, S. Inghelbrecht, A. Arien, H. Gieseler, Freeze-Drying of Nanosuspensions, 1: Freezing Rate Versus Formulation Design as Critical Factors to Preserve the Original Particle Size Distribution, Journal of Pharmaceutical Sciences, 100 (2011) 1958-1968.

[83] A. Shevchenko, L.M. Bimbo, I. Miroshnyk, J. Haarala, K. Jelinkova, K. Syrjanen, B. van Veen, J. Kiesvaara, H.A. Santos, J. Yliruusi, A new cocrystal and salts of itraconazole: comparison of solid-state properties, stability and dissolution behavior, Int J Pharm, 436 (2012) 403-409.

[84] V. Nekkanti, R. Pillai, V. Venkateshwarlu, T. Harisudhan, Development and characterization of solid oral dosage form incorporating candesartan nanoparticles, Pharmaceutical Development and Technology, 14 (2009) 290-298.

[85] S. Basa, T. Muniyappan, P. Karatgi, R. Prabhu, R. Pillai, Production and In Vitro Characterization of Solid Dosage form Incorporating Drug Nanoparticles, Drug Development and Industrial Pharmacy, 34 (2008) 1209-1218.

[86] M. Nakarani, P. Patel, J. Patel, P. Patel, R.S. Murthy, S.S. Vaghani, Cyclosporine ananosuspension: formulation, characterization and in vivo comparison with a marketed formulation, Scientia pharmaceutica, 78 (2010) 345-362. 
[87] J.-i. Jinno, N. Kamada, M. Miyake, K. Yamada, T. Mukai, M. Odomi, H. Toguchi, G.G. Liversidge, K. Higaki, T. Kimura, Effect of particle size reduction on dissolution and oral absorption of a poorly water-soluble drug, cilostazol, in beagle dogs, Journal of Controlled Release, 111 (2006) 56-64.

[88] H.S.M. Ali, P. York, A.M.A. Ali, N. Blagden, Hydrocortisone nanosuspensions for ophthalmic delivery: A comparative study between microfluidic nanoprecipitation and wet milling, Journal of Controlled Release, 149 (2011) 175-181.

[89] P.-C. Chiang, Y. Ran, K.-J. Chou, Y. Cui, H. Wong, Investigation of utilization of nanosuspension formulation to enhance exposure of 1,3-dicyclohexylurea in rats: Preparation for PK/PD study via subcutaneous route of nanosuspension drug delivery, Nanoscale Research Letters, 6 (2011) 413-413.

[90] Y. Ye, X. Zhang, T. Zhang, H. Wang, B. Wu, Design and evaluation of injectable niclosamide nanocrystals prepared by wet media milling technique, Drug Development and Industrial Pharmacy, 41 (2015) 1416-1424.

[91] P. Liu, X. Rong, J. Laru, B. van Veen, J. Kiesvaara, J. Hirvonen, T. Laaksonen, L. Peltonen, Nanosuspensions of poorly soluble drugs: Preparation and development by wet milling, International Journal of Pharmaceutics, 411 (2011) 215-222.

[92] Y. Su, S. Mesite, Production of nanoemulsion adjuvants using high shear fluid processing, 2016.

[93] G. HOMOGENIZER.

[94] J. Möschwitzer, G. Achleitner, H. Pomper, R.H. Müller, Development of an intravenously injectable chemically stable aqueous omeprazole formulation using nanosuspension technology, European Journal of Pharmaceutics and Biopharmaceutics, 58 (2004) 615-619.

[95] E. Dumay, D. Chevalier-Lucia, L. Picart-Palmade, A. Benzaria, A. Gràcia-Julià, C. Blayo, Technological aspects and potential applications of (ultra) high-pressure homogenisation, Trends in Food Science \& Technology, 31 (2013) 13-26.

[96] F. Innings, E. Hultman, F. Forsberg, B. Prakash, Understanding and analysis of wear in homogenizers for processing liquid food, Wear, 271 (2011) 2588-2598.

[97] J. Pardeike, R.H. Müller, Nanosuspensions: A promising formulation for the new phospholipase A2 inhibitor PX-18, International Journal of Pharmaceutics, 391 (2010) 322-329.

[98] S. Ganta, J.W. Paxton, B.C. Baguley, S. Garg, Formulation and pharmacokinetic evaluation of an asulacrine nanocrystalline suspension for intravenous delivery, International Journal of Pharmaceutics, 367 (2009) 179-186.

[99] S. Kobierski, K. Ofori-Kwakye, R.H. Muller, C.M. Keck, Resveratrol nanosuspensions for dermal application--production, characterization, and physical stability, Die Pharmazie, 64 (2009) 741-747.

[100] A. Dolenc, J. Kristl, S. Baumgartner, O. Planinšek, Advantages of celecoxib nanosuspension formulation and transformation into tablets, International Journal of Pharmaceutics, 376 (2009) 204-212.

[101] D. Zhang, T. Tan, L. Gao, W. Zhao, P. Wang, Preparation of Azithromycin Nanosuspensions by High Pressure Homogenization and its Physicochemical Characteristics Studies, Drug Development and Industrial Pharmacy, 33 (2007) 569-575.

[102] P. Langguth, A. Hanafy, D. Frenzel, P. Grenier, A. Nhamias, T. Ohlig, G. Vergnault, H. Spahn-Langguth, Nanosuspension formulations for low-soluble drugs: pharmacokinetic evaluation using spironolactone as model compound, Drug Dev Ind Pharm, 31 (2005) 319-329.

[103] M.A. Kassem, A.A. Abdel Rahman, M.M. Ghorab, M.B. Ahmed, R.M. Khalil, Nanosuspension as an ophthalmic delivery system for certain glucocorticoid drugs, International Journal of Pharmaceutics, 340 (2007) 126-133. 
[104] R. Xiong, W. Lu, J. Li, P. Wang, R. Xu, T. Chen, Preparation and characterization of intravenously injectable nimodipine nanosuspension, International Journal of Pharmaceutics, 350 (2008) 338-343.

[105] R. Mauludin, R.H. Müller, C.M. Keck, Kinetic solubility and dissolution velocity of rutin nanocrystals, European Journal of Pharmaceutical Sciences, 36 (2009) 502-510.

[106] Z. Zhang, X. Zhang, W. Xue, Y. YangYang, D. Xu, Y. Zhao, H. Lou, Effects of oridonin nanosuspension on cell proliferation and apoptosis of human prostatic carcinoma PC-3 cell line, International Journal of Nanomedicine, 5 (2010) 735-742.

[107] F. Lai, C. Sinico, G. Ennas, F. Marongiu, G. Marongiu, A.M. Fadda, Diclofenac nanosuspensions: Influence of preparation procedure and crystal form on drug dissolution behaviour, International Journal of Pharmaceutics, 373 (2009) 124-132.

[108] J. Hu, W.K. Ng, Y. Dong, S. Shen, R.B. Tan, Continuous and scalable process for waterredispersible nanoformulation of poorly aqueous soluble APIs by antisolvent precipitation and spray-drying, Int J Pharm, 404 (2011) 198-204.

[109] B. Sinha, R.H. Muller, J.P. Moschwitzer, Bottom-up approaches for preparing drug nanocrystals: formulations and factors affecting particle size, Int J Pharm, 453 (2013) 126-141.

[110] Y. Zhou, J. Du, L. Wang, Y. Wang, State of the art of nanocrystals technology for delivery of poorly soluble drugs, Journal of Nanoparticle Research, 18 (2016) 257.

[111] Y. Dong, W.K. Ng, J. Hu, S. Shen, R.B. Tan, Continuous production of redispersible and rapidly-dissolved fenofibrate nanoformulation by combination of microfluidics and spray drying, Powder Technology, 268 (2014) 424-428.

[112] S. Schubert, J.T. Delaney Jr, U.S. Schubert, Nanoprecipitation and nanoformulation of polymers: from history to powerful possibilities beyond poly (lactic acid), Soft Matter, 7 (2011) 1581-1588.

[113] Q. Jiang, M.D. Ward, Crystallization under nanoscale confinement, Chem Soc Rev, 43 (2014) 2066-2079.

[114] A.A. Thorat, S.V. Dalvi, Particle formation pathways and polymorphism of curcumin induced by ultrasound and additives during liquid antisolvent precipitation, CrystEngComm, 16 (2014) $11102-11114$.

[115] M.E. Matteucci, M.A. Hotze, K.P. Johnston, R.O. Williams, 3rd, Drug nanoparticles by antisolvent precipitation: mixing energy versus surfactant stabilization, Langmuir, 22 (2006) 89518959.

[116] A.A. Lonare, S.R. Patel, Antisolvent crystallization of poorly water soluble drugs, International Journal of Chemical Engineering and Applications, 4 (2013) 337.

[117] M. Kakran, N.G. Sahoo, L. Li, Z. Judeh, Particle size reduction of poorly water soluble artemisinin via antisolvent precipitation with a syringe pump, Powder technology, 237 (2013) 468476.

[118] H.K. Valo, P.H. Laaksonen, L.J. Peltonen, M.B. Linder, J.T. Hirvonen, T.J. Laaksonen, Multifunctional hydrophobin: toward functional coatings for drug nanoparticles, ACS Nano, 4 (2010) 1750-1758.

[119] A. Homayouni, F. Sadeghi, J. Varshosaz, H.A. Garekani, A. Nokhodchi, Comparing various techniques to produce micro/nanoparticles for enhancing the dissolution of celecoxib containing PVP, European Journal of Pharmaceutics and Biopharmaceutics, 88 (2014) 261-274.

[120] S. Kumar, Pharmaceutical Cocrystals: An Overview, Indian Journal of Pharmaceutical Sciences, 79 (2018) 858-871.

[121] N. Qiao, M. Li, W. Schlindwein, N. Malek, A. Davies, G. Trappitt, Pharmaceutical cocrystals: an overview, Int J Pharm, 419 (2011) 1-11.

[122] N.H. Chun, I.C. Wang, M.J. Lee, Y.T. Jung, S. Lee, W.S. Kim, G.J. Choi, Characteristics of indomethacin-saccharin (IMC-SAC) co-crystals prepared by an anti-solvent crystallization process, Eur J Pharm Biopharm, 85 (2013) 854-861. 
[123] D. Douroumis, S.A. Ross, A. Nokhodchi, Advanced methodologies for cocrystal synthesis, Adv Drug Deliv Rev, 117 (2017) 178-195.

[124] N.-H. Chun, M.-J. Lee, G.-H. Song, K.-Y. Chang, C.-S. Kim, G.J. Choi, Combined antisolvent and cooling method of manufacturing indomethacin-saccharin (IMC-SAC) co-crystal powders, Journal of Crystal Growth, 408 (2014) 112-118.

[125] A.T.N. Vo, T.D. Luu, M.N.U. Nguyen, T.V. Vo, W. Duan, P.H. Tran, T.T. Tran, SonicationAssisted Nanoprecipitation in Drug Delivery, Curr Drug Metab, 18 (2017) 145-156.

[126] J. Du, X. Li, H. Zhao, Y. Zhou, L. Wang, S. Tian, Y. Wang, Nanosuspensions of poorly water-soluble drugs prepared by bottom-up technologies, Int J Pharm, 495 (2015) 738-749.

[127] H. Rahim, A. Sadiq, S. Khan, M.A. Khan, S.M.H. Shah, Z. Hussain, R. Ullah, A.A. Shahat, K. Ibrahim, Aceclofenac nanocrystals with enhanced in vitro, in vivo performance: formulation optimization, characterization, analgesic and acute toxicity studies, Drug Des Devel Ther, 11 (2017) 2443-2452.

[128] D. Xia, P. Quan, H. Piao, H. Piao, S. Sun, Y. Yin, F. Cui, Preparation of stable nitrendipine nanosuspensions using the precipitation-ultrasonication method for enhancement of dissolution and oral bioavailability, European Journal of Pharmaceutical Sciences, 40 (2010) 325-334.

[129] K.A. Soliman, H.K. Ibrahim, M.M. Ghorab, Effects of different combinations of nanocrystallization technologies on avanafil nanoparticles: in vitro, in vivo and stability evaluation, Int J Pharm, 517 (2017) 148-156.

[130] S. Aher, R. Dhumal, K. Mahadik, A. Paradkar, P. York, Ultrasound assisted cocrystallization from solution (USSC) containing a non-congruently soluble cocrystal component pair: Caffeine/maleic acid, Eur J Pharm Sci, 41 (2010) 597-602.

[131] R. Al-Kassas, M. Bansal, J. Shaw, Nanosizing techniques for improving bioavailability of drugs, J Control Release, 260 (2017) 202-212.

[132] J. Zhong, Z. Shen, Y. Yang, J. Chen, Preparation and characterization of uniform nanosized cephradine by combination of reactive precipitation and liquid anti-solvent precipitation under high gravity environment, Int J Pharm, 301 (2005) 286-293.

[133] J.-F. Chen, J.-Y. Zhang, Z.-G. Shen, J. Zhong, J. Yun, Preparation and characterization of amorphous cefuroxime axetil drug nanoparticles with novel technology: high-gravity antisolvent precipitation, Industrial \& engineering chemistry research, 45 (2006) 8723-8727.

[134] Z. Hong, W. Jiexin, H. ZHANG, S. Zhigang, J. Yun, C. Jianfeng, Facile preparation of danazol nanoparticles by high-gravity anti-solvent precipitation (HGAP) method, Chinese Journal of Chemical Engineering, 17 (2009) 318-323.

[135] H. Chiou, L. Li, T. Hu, H.K. Chan, J.F. Chen, J. Yun, Production of salbutamol sulfate for inhalation by high-gravity controlled antisolvent precipitation, Int J Pharm, 331 (2007) 93-98.

[136] B.K. Johnson, R.K. Prud'homme, Chemical processing and micromixing in confined impinging jets, AIChE Journal, 49 (2003) 2264-2282.

[137] W.S. Saad, R.K. Prud'homme, Principles of nanoparticle formation by flash nanoprecipitation, Nano Today, 11 (2016) 212-227.

[138] J. Bteich, S.A. McManus, M.J. Ernsting, M.Z. Mohammed, R.K. Prud'homme, K.K. Sokoll, Using Flash Nanoprecipitation To Produce Highly Potent and Stable Cellax Nanoparticles from Amphiphilic Polymers Derived from Carboxymethyl Cellulose, Polyethylene Glycol, and Cabazitaxel, Molecular Pharmaceutics, 14 (2017) 3998-4007.

[139] X. Chen, T.J. Young, M. Sarkari, R.O. Williams, 3rd, K.P. Johnston, Preparation of cyclosporine A nanoparticles by evaporative precipitation into aqueous solution, Int J Pharm, 242 (2002) 3-14.

[140] P. Sinswat, X. Gao, M.J. Yacaman, R.O. Williams, 3rd, K.P. Johnston, Stabilizer choice for rapid dissolving high potency itraconazole particles formed by evaporative precipitation into aqueous solution, Int J Pharm, 302 (2005) 113-124.

[141] G.M. Whitesides, The Origins and the Future of Microfluidics, Nature, 442 (2006) 368-373. 
[142] F. Fontana, M.P. Ferreira, A. Correia, J. Hirvonen, H.A. Santos, Microfluidics as a cuttingedge technique for drug delivery applications, Journal of Drug Delivery Science and Technology, 34 (2016) 76-87.

[143] Z. Liu, Y. Li, W. Li, C. Xiao, D. Liu, C. Dong, M. Zhang, E. Makila, M. Kemell, J. Salonen, J.T. Hirvonen, H. Zhang, D. Zhou, X. Deng, H.A. Santos, Multifunctional Nanohybrid Based on Porous Silicon Nanoparticles, Gold Nanoparticles, and Acetalated Dextran for Liver Regeneration and Acute Liver Failure Theranostics, Adv Mater, (2017).

[144] H. Zhang, Y. Zhu, L. Qu, H. Wu, H. Kong, Z. Yang, D. Chen, E. Makila, J. Salonen, H.A. Santos, M. Hai, D.A. Weitz, Gold Nanorods Conjugated Porous Silicon Nanoparticles Encapsulated in Calcium Alginate Nano Hydrogels Using Microemulsion Templates, Nano Lett, 18 (2018) 14481453.

[145] F. Fontana, M.A. Shahbazi, D. Liu, H. Zhang, E. Makila, J. Salonen, J.T. Hirvonen, H.A. Santos, Multistaged Nanovaccines Based on Porous Silicon@Acetalated Dextran@Cancer Cell Membrane for Cancer Immunotherapy, Adv Mater, 29 (2017).

[146] D. Liu, H. Zhang, S. Cito, J. Fan, E. Makila, J. Salonen, J. Hirvonen, T.M. Sikanen, D.A. Weitz, H.A. Santos, Core/Shell Nanocomposites Produced by Superfast Sequential Microfluidic Nanoprecipitation, Nano Lett, 17 (2017) 606-614.

[147] W. Li, D. Liu, H. Zhang, A. Correia, E. Makila, J. Salonen, J. Hirvonen, H.A. Santos, Microfluidic assembly of a nano-in-micro dual drug delivery platform composed of halloysite nanotubes and a pH-responsive polymer for colon cancer therapy, Acta Biomater, 48 (2017) 238246.

[148] N. Kerdsakundee, W. Li, J.P. Martins, Z. Liu, F. Zhang, M. Kemell, A. Correia, Y. Ding, M. Airavaara, J. Hirvonen, R. Wiwattanapatapee, H.A. Santos, Multifunctional NanotubeMucoadhesive Poly(methyl vinyl ether-co-maleic acid)@Hydroxypropyl Methylcellulose Acetate Succinate Composite for Site-Specific Oral Drug Delivery, Adv Healthc Mater, 6 (2017).

[149] H. Zhang, D. Liu, L. Wang, Z. Liu, R. Wu, A. Janoniene, M. Ma, G. Pan, L. Baranauskiene, L. Zhang, W. Cui, V. Petrikaite, D. Matulis, H. Zhao, J. Pan, H.A. Santos, Microfluidic Encapsulation of Prickly Zinc-Doped Copper Oxide Nanoparticles with VD1142 Modified Spermine Acetalated Dextran for Efficient Cancer Therapy, Adv Healthc Mater, 6 (2017).

[150] F. Kong, H. Zhang, X. Qu, X. Zhang, D. Chen, R. Ding, E. Mäkilä, J. Salonen, H.A. Santos, M. Hai, Gold Nanorods, DNA Origami, and Porous Silicon Nanoparticle-functionalized Biocompatible Double Emulsion for Versatile Targeted Therapeutics and Antibody Combination Therapy, Advanced Materials, 28 (2016) 10195-10203.

[151] F. Kong, H. Zhang, X. Zhang, D. Liu, D. Chen, W. Zhang, L. Zhang, H.A. Santos, M. Hai, Biodegradable photothermal and pH responsive calcium carbonate@ phospholipid@ acetalated dextran hybrid platform for advancing biomedical applications, Advanced Functional Materials, 26 (2016) 6158-6169.

[152] F. Araújo, N. Shrestha, M.J. Gomes, B. Herranz-Blanco, D. Liu, J. Hirvonen, P. Granja, H. Santos, B. Sarmento, In vivo dual-delivery of glucagon like peptide-1 (GLP-1) and dipeptidyl peptidase-4 (DPP4) inhibitor through composites prepared by microfluidics for diabetes therapy, Nanoscale, 8 (2016) 10706-10713.

[153] F. Araujo, N. Shrestha, M.-A. Shahbazi, D. Liu, B. Herranz-Blanco, E.M. Mäkilä, J.J. Salonen, J.T. Hirvonen, P.L. Granja, B. Sarmento, Microfluidic assembly of a multifunctional tailorable composite system designed for site specific combined oral delivery of peptide drugs, ACS nano, 9 (2015) 8291-8302.

[154] F. Kong, X. Zhang, H. Zhang, X. Qu, D. Chen, M. Servos, E. Mäkilä, J. Salonen, H.A. Santos, M. Hai, Inhibition of Multidrug Resistance of Cancer Cells by Co-Delivery of DNA Nanostructures and Drugs Using Porous Silicon Nanoparticles@ Giant Liposomes, Advanced Functional Materials, 25 (2015) 3330-3340. 
[155] D. Liu, S. Cito, Y. Zhang, C.F. Wang, T.M. Sikanen, H.A. Santos, A versatile and robust microfluidic platform toward high throughput synthesis of homogeneous nanoparticles with tunable properties, Advanced Materials, 27 (2015) 2298-2304.

[156] B. Herranz-Blanco, D. Liu, E. Mäkilä, M.A. Shahbazi, E. Ginestar, H. Zhang, V. Aseyev, V. Balasubramanian, J. Salonen, J. Hirvonen, On-Chip Self-Assembly of a Smart Hybrid Nanocomposite for Antitumoral Applications, Advanced Functional Materials, 25 (2015) 14881497.

[157] D. Liu, H. Zhang, F. Fontana, J.T. Hirvonen, H.1.A. Santos, Microfluidic-assisted fabrication of carriers for controlled drug delivery, Lab Chip, 17 (2017) 1856-1883.

[158] D. Liu, H. Zhang, E. Mäkilä, J. Fan, B. Herranz-Blanco, C.-F. Wang, R. Rosa, A.J. Ribeiro, J. Salonen, J. Hirvonen, Microfluidic assisted one-step fabrication of porous silicon@ acetalated dextran nanocomposites for precisely controlled combination chemotherapy, Biomaterials, 39 (2015) 249-259.

[159] H. Zhang, D. Liu, M.A. Shahbazi, E. Mäkilä, B. Herranz-Blanco, J. Salonen, J. Hirvonen, H.A. Santos, Fabrication of a Multifunctional Nano-in-micro Drug Delivery Platform by Microfluidic Templated Encapsulation of Porous Silicon in Polymer Matrix, Advanced Materials, 26 (2014) 4497-4503.

[160] J. Pessi, H.A. Santos, I. Miroshnyk, D.A. Weitz, S. Mirza, Microfluidics-assisted engineering of polymeric microcapsules with high encapsulation efficiency for protein drug delivery, International journal of pharmaceutics, 472 (2014) 82-87.

[161] D. Liu, H. Zhang, B. Herranz-Blanco, E. Mäkilä, V.P. Lehto, J. Salonen, J. Hirvonen, H.A. Santos, Microfluidic Assembly of Monodisperse Multistage $\mathrm{pH}$-Responsive Polymer/Porous Silicon Composites for Precisely Controlled Multi-Drug Delivery, Small, 10 (2014) 2029-2038.

[162] B. Herranz-Blanco, L.R. Arriaga, E. Mäkilä, A. Correia, N. Shrestha, S. Mirza, D.A. Weitz, J. Salonen, J. Hirvonen, H.A. Santos, Microfluidic assembly of multistage porous silicon-lipid vesicles for controlled drug release, Lab on a Chip, 14 (2014) 1083-1086.

[163] D. Liu, B.r. Herranz-Blanco, E. Mäkilä, L.R. Arriaga, S. Mirza, D.A. Weitz, N. Sandler, J. Salonen, J. Hirvonen, H.l.A. Santos, Microfluidic templated mesoporous silicon-solid lipid microcomposites for sustained drug delivery, ACS applied materials \& interfaces, 5 (2013) 12127 12134.

[164] P.M. Valencia, O.C. Farokhzad, R. Karnik, R. Langer, Microfluidic technologies for accelerating the clinical translation of nanoparticles, Nat Nanotechnol, 7 (2012) 623-629.

[165] R. Karnik, F. Gu, P. Basto, C. Cannizzaro, L. Dean, W. Kyei-Manu, R. Langer, O.C. Farokhzad, Microfluidic platform for controlled synthesis of polymeric nanoparticles, Nano Letters, 8 (2008) 2906-2912.

[166] D. Liu, H. Zhang, F. Fontana, J.T. Hirvonen, H.A. Santos, Current developments and applications of microfluidic technology toward clinical translation of nanomedicines, Adv Drug Deliv Rev, (2017).

[167] Q. Feng, J. Sun, X. Jiang, Microfluidics-mediated assembly of functional nanoparticles for cancer-related pharmaceutical applications, Nanoscale, 8 (2016) 12430-12443.

[168] P.A. Zhu, L.Q. Wang, Passive and active droplet generation with microfluidics: a review, Lab on a Chip, 17 (2017) 34-75.

[169] J. Wang, Y. Song, Microfluidic Synthesis of Nanohybrids, Small, 13 (2017) 1604084-n/a.

[170] P.N. Nge, C.I. Rogers, A.T. Woolley, Advances in Microfluidic Materials, Functions, Integration, and Applications, Chem Rev, 113 (2013) 2550-2583.

[171] W.K.T. Coltro, S.M. Lunte, E. Carrilho, Comparison of the analytical performance of electrophoresis microchannels fabricated in PDMS, glass, and polyester-toner, Electrophoresis, 29 (2008) 4928-4937.

[172] C. Iliescu, H. Taylor, M. Avram, J.M. Miao, S. Franssila, A practical guide for the fabrication of microfluidic devices using glass and silicon, Biomicrofluidics, 6 (2012). 
[173] T.T. Kong, J. Wu, M. To, K.W.K. Yeung, H.C. Shum, L.Q. Wang, Droplet based microfluidic fabrication of designer microparticles for encapsulation applications, Biomicrofluidics, 6 (2012).

[174] W.J. Duncanson, T. Lin, A.R. Abate, S. Seiffert, R.K. Shah, D.A. Weitz, Microfluidic synthesis of advanced microparticles for encapsulation and controlled release, Lab on a Chip, 12 (2012) 2135-2145.

[175] B. Herranz-Blanco, E. Ginestar, H. Zhang, J. Hirvonen, H.A. Santos, Microfluidics platform for glass capillaries and its application in droplet and nanoparticle fabrication, Int J Pharm, 516 (2017) 100-105.

[176] R. Vasiliauskas, D. Liu, S. Cito, H. Zhang, M.-A. Shahbazi, T. Sikanen, L. Mazutis, H.l.A. Santos, Simple microfluidic approach to fabricate monodisperse hollow microparticles for multidrug delivery, ACS applied materials \& interfaces, 7 (2015) 14822-14832.

[177] H. Zhao, J.X. Wang, Q.A. Wang, J.F. Chen, J. Yun, Controlled liquid antisolvent precipitation of hydrophobic pharmaceutical nanoparticles in a microchannel reactor, Industrial \& Engineering Chemistry Research, 46 (2007) 8229-8235.

[178] S. Dev, J. Toster, S. Vadhan Prasanna, M. Fitzgerald, K. Swaminathan Iyer, C.L. Raston, Suppressing regrowth of microfluidic generated drug nanocrystals using polyelectrolyte coatings, RSC Advances, 3 (2013) 695-698.

[179] T. Panagiotou, S.V. Mesite, R.J. Fisher, Production of Norfloxacin Nanosuspensions Using Microfluidics Reaction Technology through Solvent/Antisolvent Crystallization, Industrial \& Engineering Chemistry Research, 48 (2009) 1761-1771.

[180] K. Tahara, M. Nishikawa, K. Matsui, K. Hisazumi, R. Onodera, Y. Tozuka, H. Takeuchi, In Vitro and In Vivo Characterization of Drug Nanoparticles Prepared Using PureNano (TM) Continuous Crystallizer to Improve the Bioavailability of Poorly Water Soluble Drugs, Pharm ResDordr, 33 (2016) 2259-2268.

[181] S. Dev, P. Prabhakaran, L. Filgueira, K.S. Iyer, C.L. Raston, Microfluidic fabrication of cationic curcumin nanoparticles as an anti-cancer agent, Nanoscale, 4 (2012) 2575-2579.

[182] S. Dev, K.S. Iyer, C.L. Raston, Nanosized drug formulations under microfluidic continuous flow, Lab on a Chip, 11 (2011) 3214-3217.

[183] D. Liu, C.R. Bernuz, J. Fan, W. Li, A. Correia, J.T. Hirvonen, H.A. Santos, A nano-in-nano vector: merging the best of both polymeric nanoparticles and drug nanocrystals, Advanced Functional Materials, 27 (2017) 1604508.

[184] R. Campardelli, L. Baldino, E. Reverchon, Supercritical fluids applications in nanomedicine, The Journal of Supercritical Fluids, 101 (2015) 193-214.

[185] M.S. Kim, S.J. Jin, J.S. Kim, H.J. Park, H.S. Song, R.H. Neubert, S.J. Hwang, Preparation, characterization and in vivo evaluation of amorphous atorvastatin calcium nanoparticles using supercritical antisolvent (SAS) process, Eur J Pharm Biopharm, 69 (2008) 454-465.

[186] S.A. Shoyele, S. Cawthorne, Particle engineering techniques for inhaled biopharmaceuticals, Adv Drug Deliv Rev, 58 (2006) 1009-1029.

[187] L. Padrela, M.A. Rodrigues, S.P. Velaga, A.C. Fernandes, H.A. Matos, E.G. de Azevedo, Screening for pharmaceutical cocrystals using the supercritical fluid enhanced atomization process, The Journal of Supercritical Fluids, 53 (2010) 156-164.

[188] E. Reverchon, Supercritical antisolvent precipitation of micro-and nano-particles, The journal of supercritical fluids, 15 (1999) 1-21.

[189] C. Vemavarapu, M.J. Mollan, M. Lodaya, T.E. Needham, Design and process aspects of laboratory scale SCF particle formation systems, Int J Pharm, 292 (2005) 1-16.

[190] E. Badens, Y. Masmoudi, A. Mouahid, C. Crampon, Current situation and perspectives in drug formulation by using supercritical fluid technology, The Journal of Supercritical Fluids, (2017). 
[191] M. Mukhopadhyay, S.V. Dalvi, Mass and heat transfer analysis of SAS: effects of thermodynamic states and flow rates on droplet size, The Journal of supercritical fluids, 30 (2004) 333-348.

[192] Y. Wang, X. Han, J. Wang, Y. Wang, Preparation, characterization and in vivo evaluation of amorphous tacrolimus nanosuspensions produced using $\mathrm{CO} 2$-assisted in situ nanoamorphization method, Int J Pharm, 505 (2016) 35-41.

[193] M.J. Whitaker, J. Hao, O.R. Davies, G. Serhatkulu, S. Stolnik-Trenkic, S.M. Howdle, K.M. Shakesheff, The production of protein-loaded microparticles by supercritical fluid enhanced mixing and spraying, J Control Release, 101 (2005) 85-92.

[194] D.R. Perinelli, G. Bonacucina, M. Cespi, A. Naylor, M. Whitaker, G.F. Palmieri, G. Giorgioni, L. Casettari, Evaluation of P (L) LA-PEG-P (L) LA as processing aid for biodegradable particles from gas saturated solutions (PGSS) process, International journal of pharmaceutics, 468 (2014) 250-257.

[195] C. Atila, N. Yıldız, A. Çalımlı, Particle size design of digitoxin in supercritical fluids, The Journal of Supercritical Fluids, 51 (2010) 404-411.

[196] D. Bolten, M. Türk, Micronisation of carbamazepine through rapid expansion of supercritical solution (RESS), The Journal of Supercritical Fluids, 62 (2012) 32-40.

[197] Z. Huang, G.-B. Sun, Y.C. Chiew, S. Kawi, Formation of ultrafine aspirin particles through rapid expansion of supercritical solutions (RESS), Powder Technology, 160 (2005) 127-134.

[198] J. Huang, T. Moriyoshi, Fabrication of fine powders by RESS with a clearance nozzle, The Journal of supercritical fluids, 37 (2006) 292-297.

[199] A. Keshavarz, J. Karimi-Sabet, A. Fattahi, A. Golzary, M. Rafiee-Tehrani, F.A. Dorkoosh, Preparation and characterization of raloxifene nanoparticles using rapid expansion of supercritical solution (RESS), The Journal of Supercritical Fluids, 63 (2012) 169-179.

[200] S.K. Sharma, R. Jagannathan, High throughput RESS processing of sub-10 nm ibuprofen nanoparticles, The Journal of Supercritical Fluids, 109 (2016) 74-79.

[201] M.C. Paisana, K.C. Müllers, M.A. Wahl, J.F. Pinto, Production and stabilization of olanzapine nanoparticles by rapid expansion of supercritical solutions (RESS), The Journal of Supercritical Fluids, 109 (2016) 124-133.

[202] X. Zhao, Y. Zu, Q. Li, M. Wang, B. Zu, X. Zhang, R. Jiang, C. Zu, Preparation and characterization of camptothecin powder micronized by a supercritical antisolvent (SAS) process, The Journal of Supercritical Fluids, 51 (2010) 412-419.

[203] S.-C. Chang, M.-J. Lee, H.-M. Lin, Role of phase behavior in micronization of lysozyme via a supercritical anti-solvent process, Chemical Engineering Journal, 139 (2008) 416-425.

[204] A. Montes, A. Tenorio, M. Gordillo, C. Pereyra, E.M. de La Ossa, Screening design of experiment applied to supercritical antisolvent precipitation of amoxicillin: exploring new miscible conditions, The Journal of Supercritical Fluids, 51 (2010) 399-403.

[205] J. Zhang, Y. Huang, D. Liu, Y. Gao, S. Qian, Preparation of apigenin nanocrystals using supercritical antisolvent process for dissolution and bioavailability enhancement, European Journal of Pharmaceutical Sciences, 48 (2013) 740-747.

[206] S.M. Dizaj, Z. Vazifehasl, S. Salatin, K. Adibkia, Y. Javadzadeh, Nanosizing of drugs: Effect on dissolution rate, Res Pharm Sci, 10 (2015) 95-108.

[207] A. Sosnik, K.P. Seremeta, Advantages and challenges of the spray-drying technology for the production of pure drug particles and drug-loaded polymeric carriers, Adv Colloid Interface Sci, 223 (2015) 40-54.

[208] A.B.D. Nandiyanto, K. Okuyama, Progress in developing spray-drying methods for the production of controlled morphology particles: From the nanometer to submicrometer size ranges, Advanced Powder Technology, 22 (2011) 1-19.

[209] G. Shete, A.K. Bansal, NanoCrySP technology for generation of drug nanocrystals: translational aspects and business potential, Drug Deliv Transl Res, 6 (2016) 392-398. 
[210] M. Beck-Broichsitter, C. Schweiger, T. Schmehl, T. Gessler, W. Seeger, T. Kissel, Characterization of novel spray-dried polymeric particles for controlled pulmonary drug delivery, J Control Release, 158 (2012) 329-335.

[211] K. Schmid, C. Arpagaus, W. Friess, Evaluation of the Nano Spray Dryer B-90 for pharmaceutical applications, Pharm Dev Technol, 16 (2011) 287-294.

[212] H. de Waard, W.L. Hinrichs, H.W. Frijlink, A novel bottom-up process to produce drug nanocrystals: controlled crystallization during freeze-drying, J Control Release, 128 (2008) 179183.

[213] J. Hu, K.P. Johnston, R.O. Williams III, Spray freezing into liquid (SFL) particle engineering technology to enhance dissolution of poorly water soluble drugs: organic solvent versus organic/aqueous co-solvent systems, European journal of pharmaceutical sciences, 20 (2003) 295303.

[214] V.K. Pawar, Y. Singh, J.G. Meher, S. Gupta, M.K. Chourasia, Engineered nanocrystal technology: in-vivo fate, targeting and applications in drug delivery, J Control Release, 183 (2014) 51-66.

[215] B.E. Rabinow, Nanosuspensions in drug delivery, Nat Rev Drug Discov, 3 (2004) 785-796.

[216] A. Tuomela, J. Saarinen, C.J. Strachan, J. Hirvonen, L. Peltonen, Production, applications and in vivo fate of drug nanocrystals, Journal of Drug Delivery Science and Technology, 34 (2016) 2131.

[217] R.B. Chavan, R. Thipparaboina, B. Yadav, N.R. Shastri, Continuous manufacturing of cocrystals: challenges and prospects, Drug Deliv Transl Res, (2018).

[218] N. Radacsi, R. Ambrus, T. Szunyogh, P. Szabó-Révész, A. Stankiewicz, A. Van Der Heijden, J.H. Ter Horst, Electrospray crystallization for nanosized pharmaceuticals with improved properties, Crystal Growth \& Design, 12 (2012) 3514-3520.

[219] M. Wang, G.C. Rutledge, A.S. Myerson, B.L. Trout, Production and characterization of carbamazepine nanocrystals by electrospraying for continuous pharmaceutical manufacturing, Journal of pharmaceutical sciences, 101 (2012) 1178-1188.

[220] S. Patil, J. Kulkarni, K. Mahadik, Exploring the potential of electrospray technology in cocrystal synthesis, Industrial \& Engineering Chemistry Research, 55 (2016) 8409-8414.

[221] S. Patil, V. Ujalambkar, A. Mahadik, Electrospray technology as a probe for cocrystal synthesis: influence of solvent and coformer structure, Journal of Drug Delivery Science and Technology, 39 (2017) 217-222. 


\section{Combination Technology}

\section{Top-Down Approach}

Milling

High-pressure Homogenization
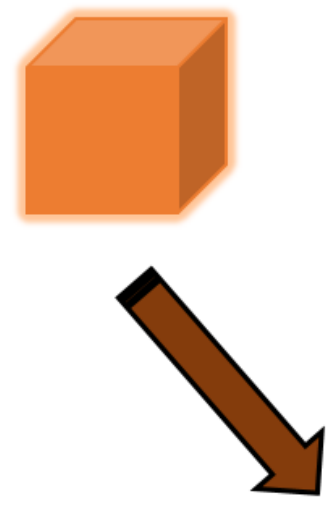

Graphical abstract

\section{Bottom-up Approach}

Solvent-Antisolvent

Supercritical Fluid

Solvent Removal
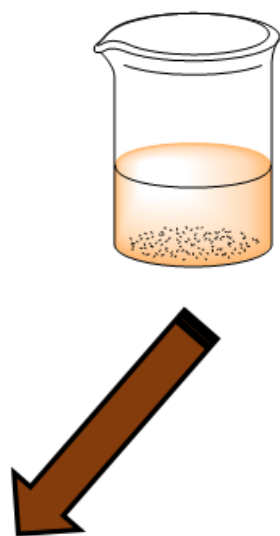